الإنفتاح الإكتروني لأعضاء مجالس إدارات الجمعيات التعاونية الزراعية ببعض مراكز محافظة البحيرة

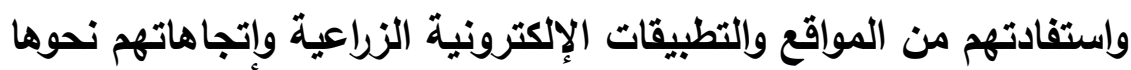 \\ مصطفي صبري مصطفى صالح'، مى أحمد رأفت النطاوى 'و محمد صبري مصطفى صالح'

\section{المقدمة والمشكلة البحثية}

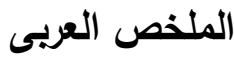

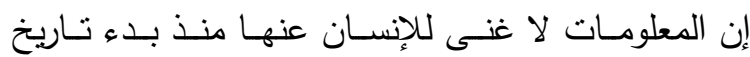

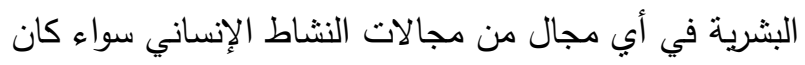

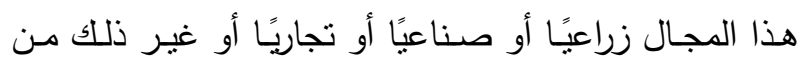

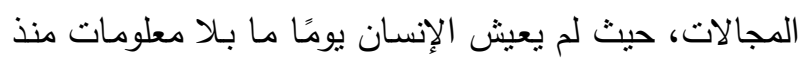

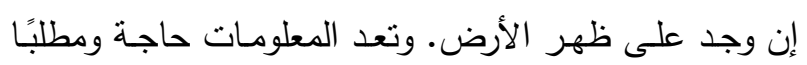
أساسيًا في حياة الإنسان، كما أنها موردًا اقتصاديًا واستثماريًا، الأنيا.

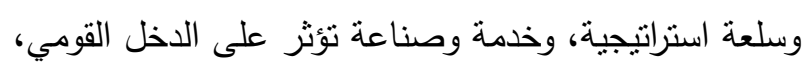

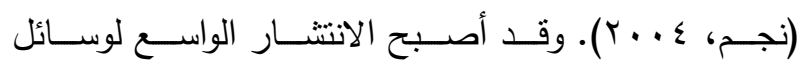

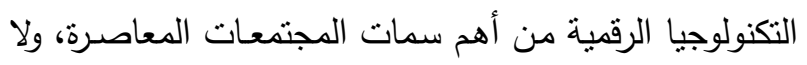

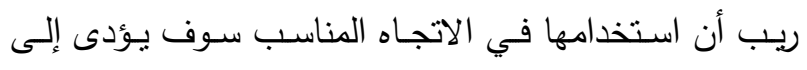

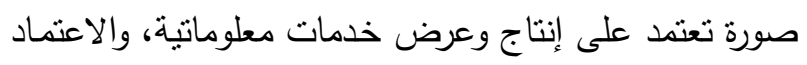

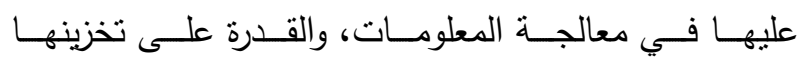

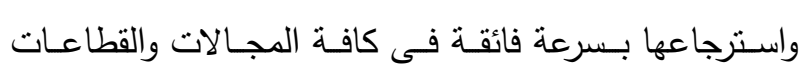

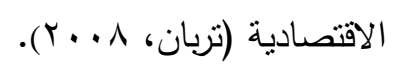

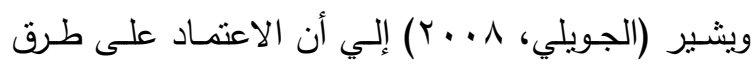

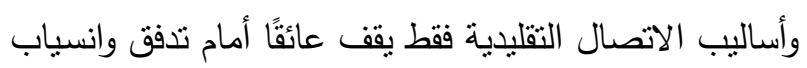

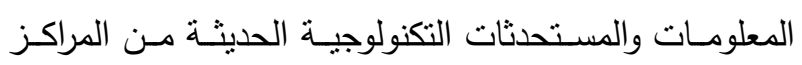

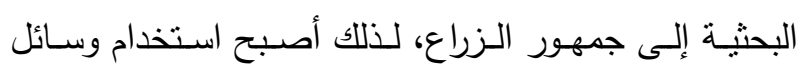

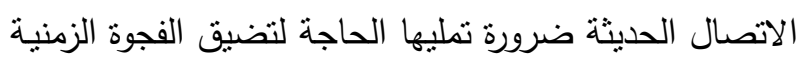

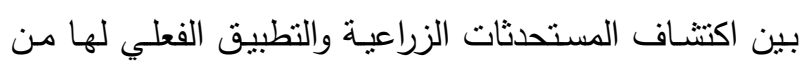

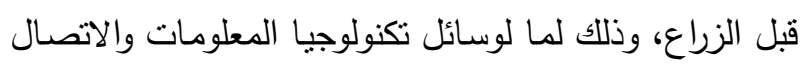

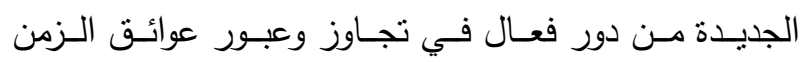

يسـتهـف هــا البحـث بصـفة رئيسـية، دراســة الإنفتــاح الإكتروني لأعضاء مجالس إدارات الجميات التعاونية الززاعية

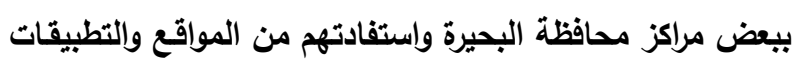
الإكترونية الزراعية وإتجاهاتهم نحوها. وقد استخدم الاستبيان

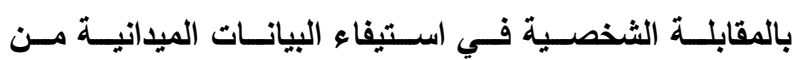

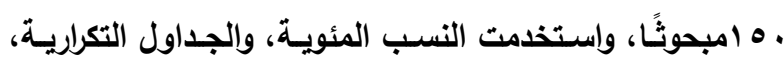

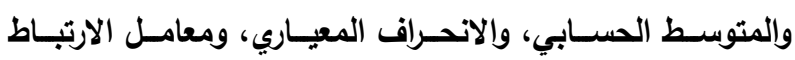
البسـيط، والانحــار المتعدد، إختبـار تحليـل التبـاين لإختبـار

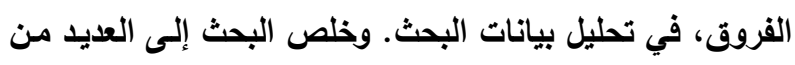

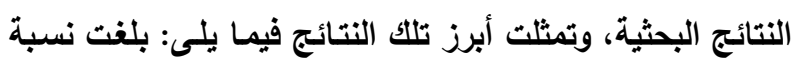

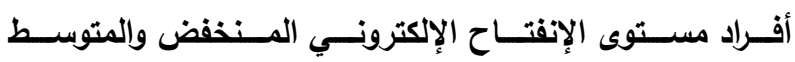

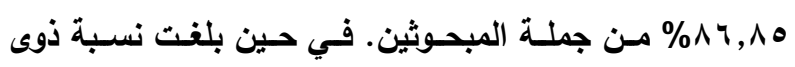

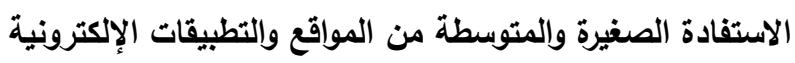

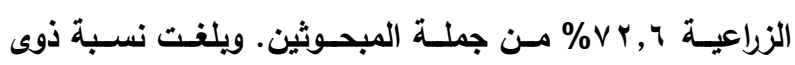
الاتجاهات السلبية والمحايدة نحو المواقع والتطبيقات الإلكترونية

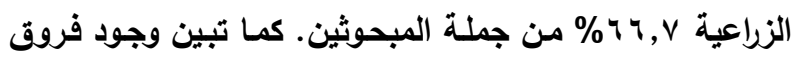
معنوية بين المراكز الثلاثة المدروسة وفقًا لمتوسطات درجات كل كل

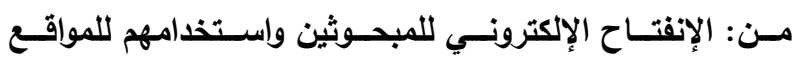
والتطبيقات الإلكترونية الزراعية، واتجاهاتهم نحوها.

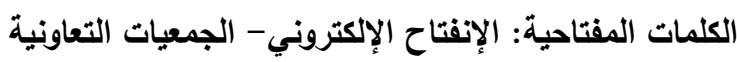

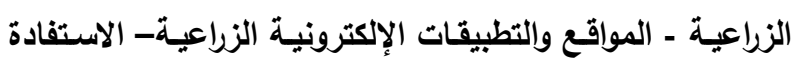

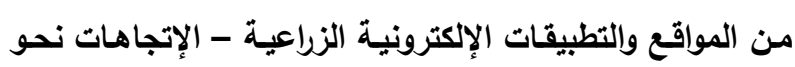
المواقع والتطبيقات الإكترونية الزراعية.

معرف الوثيقة الرقمى: 10.21608/asejaiqjsae.2021.209920 ' ' قسم التعليم الإرشادي الزراعي- كلبة الزراعة - جامعة الإنكندرية. 
مجـال تكنولوجيـا المعلومـات والاتصـال . كمـا قامـت بإنثـاء

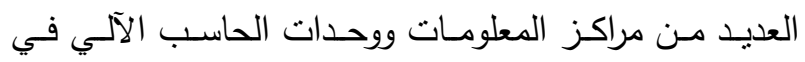
مختلـف المجـالات الزراعيـة البحثيـة والإرشـادية والخدميـة والإدارية، بغرض خدمة العمل في القطاع الزراعي، وضمان

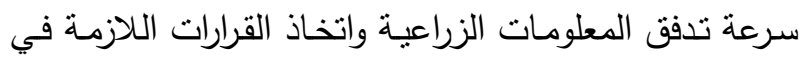

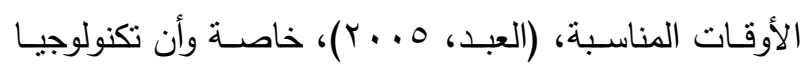

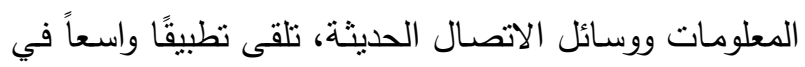
مجال الارشاد الزراعي في كثير من الدول. وفى هذا السياق

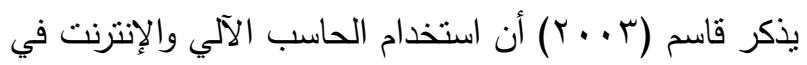
مجال الإرشـاد الزراعي قد أصبح يشكل بيئة مناسبة لتكامل ونشـر واسـتخدام المعرفـة والمعلومـات الزراعيـة، واسـتخلال القدرات التعليمية والاتصـالية لتفعيل التكامل بين المستخدمين ولت ولين لتكنولوجيـا المعلومـات والاتصـالات، والقـائمين على جهـاز الإرثـاد الزراعي، ممـا يسـاعد على تقديم خدمات معلوماتيـة

جديدة للمناطق الريفية.

ولاريــب أن التطــورات السـريعة فـي مجــال تكنولوجيــا

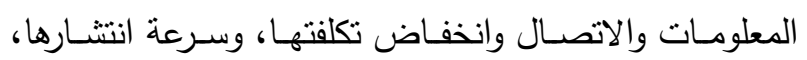
وسـهولة اسـتخدامها قد أتـاح الفرصـة لتحسـين وتطـوير نقل المعرفـة الزراعيـة، مـن خـلال تـوفير قنـوات اتصـالية واسـعة ومنتوعة لخدمة القطاع الزراعي ونشر كل ما هو جديد ومفيد

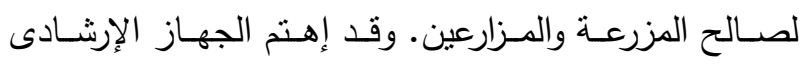
الزراعس، وغيره مـن مقدمى الخدمات الزراعيـة ممثلين فى الزي

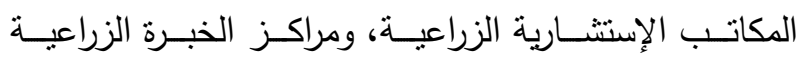

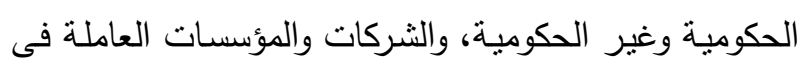

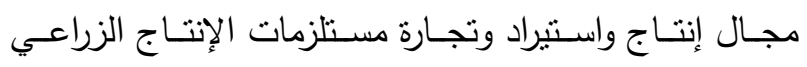

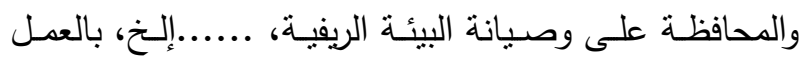
على تطـوير وسـائلهم في الوصـول إلى عملائهم وتـرويج سلعهم وخدماتهم، (hill, 2012). ومن ثم تم تصميم العديد من ون المواقع الإلكترونية والتطبيقات الزراعية التي تحمل كل ما يهرم

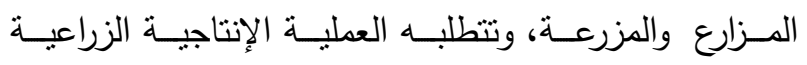

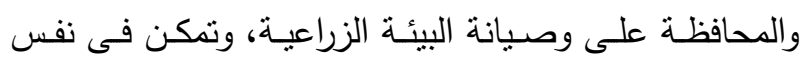

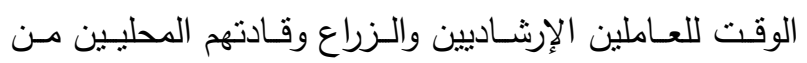

والمسـافة، والقـدرة الفائقـة علـى نشــر وتبــادل المعلومــات والمعارف بسرعة كبيرة مما يسهم في تحقيق أهداف التتمية. وقد استوجب ذلك تحديث وتطوير القطاع الزراعي من خلال الأجهزة المعنية، ويعتبر الإرشاد الزراعي أحد النظم التعليمية غير الرسمية التي تستهدف تحديث وتطوير ذلك القطاع من خلال نقل التكنولوجيا المستحدثة التي تتتجها المراكز البحثية الزراعية إلى التطبيتق الميداني، وتحديد المشكلات الزراعية ونقل الحلول المناسبة لها إلى أفراد المجتمع لإحداث تتميـة ونية

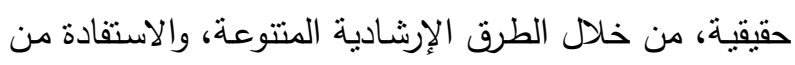
التغييرات التكنولوجية القائمة على توظيف وسائل التكنولوجيا الرقمية التي أثرت على مختلف النشاط الإنساني (عبدالواحدِ،

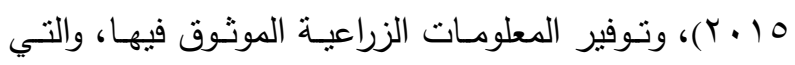
تعتبر من أهم أهداف الإرشاد الزراعي، (Renwick, 2009). وإزاء توجـهـ الدولـة إلـى تعمـيم الاسـتفادة مـن الثـبكة

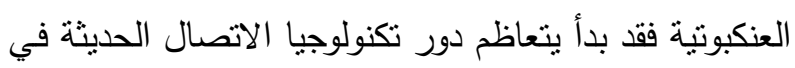
مختلف قطاعات الدولة بصفة عامة والقطاع الزراعي بصفة

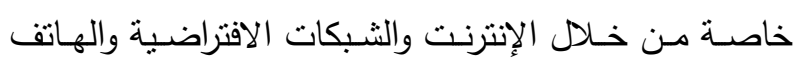
المحمول، وشبكات التواصل الإجتمـاعى كمصسادر معلومات للزراع إلى الحد الذي قَلَص دور الإرشـاد الزراعي كمصدر

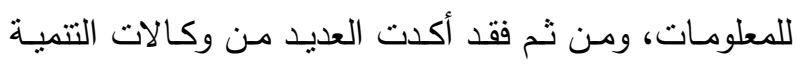
الدولية على أهمية تغيير دور الارشاد الزراعي لكى يتأقلم مع الواقع الجديـد بحيث يقوم بـدور الميسر أو الوسيط لتعظيم

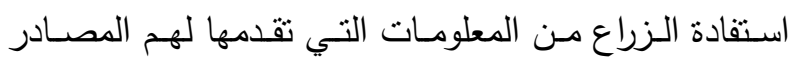
المتعددة، (قاسم، 10 • ب) نقلًا عن(Soyemi, 2014). ونظـرًا لأهميـة اسـتخدام وتوظيـف تكنولوجيـا المعلومـات والاتصالات في العمل الإرشادي الزراعي، وقدرتها على حل

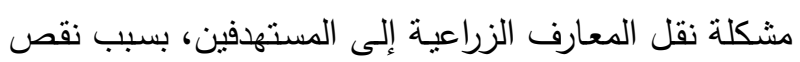
عدد المرشـدين الزراعيين وقلـة وسـائل المواصـلات اللازمـة لهم، فقد أولت وزارة الزراعـة واستصـلاح الأراضـي اهتمائًا كبيرًا في استراتيجيتها للتتمية الزراعية المستدامة على ضرورة

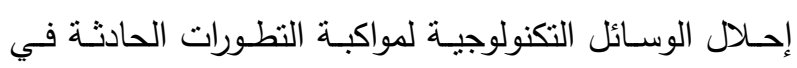


r. التعـرف على درجــة اسـتفادة أعضـــاء مجـالس إدارات

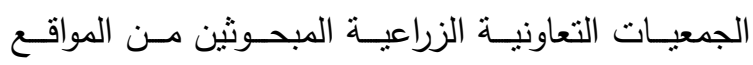
والتطبيقات الإكترونية الزراعية.

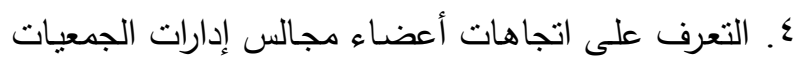

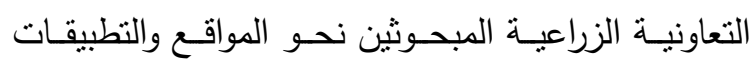
الإلكترونية الزراعية.

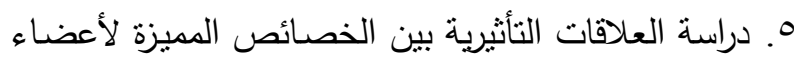

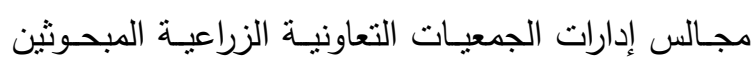

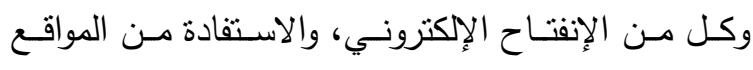

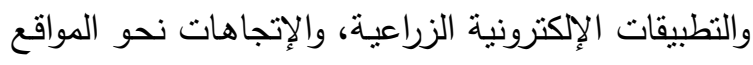
والنطبيقات الإلكترونية الزراعية.

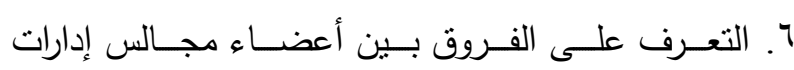

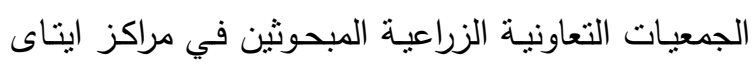

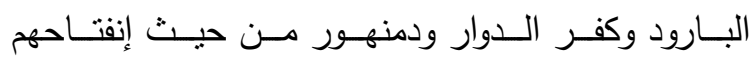
الإلكتروني واستفادتهم من المواقع والتطبيقات الإلكترونية

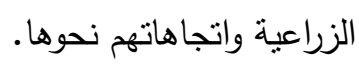

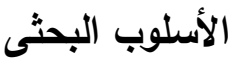

\section{أولاً: المصطحات البحثية} (1) المواقع والتطبيقات الإكترونيـة الزراعيـة: ويقصد بها

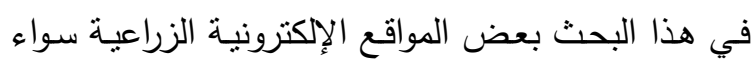

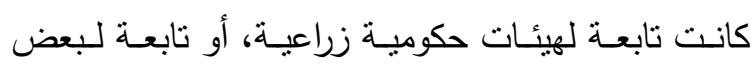

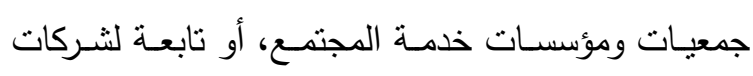

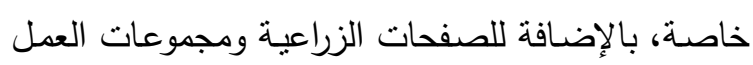

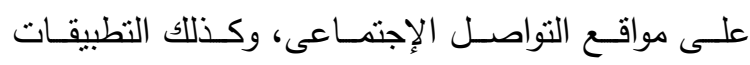
الإكترونية الزراعية.

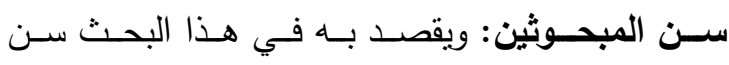

المبحوث مقدرًا لأقرب سنة ميلادية وقت إجراء البحث.

(r) المستوى التعليمى للمبحوث: ويقصد به في هذا البحث

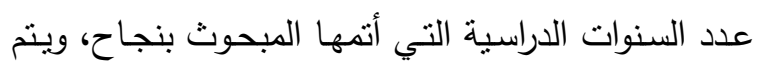
التعبير عنه بقيمة رقمية.
التردد عليها في الوقت المناسب واستخدامها والإستفادة منها،

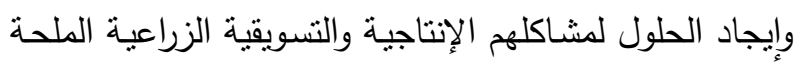
وغيرها، خاصة وأن بعض الدراسات قد أظهرت وجود رغبة

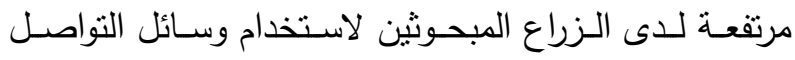

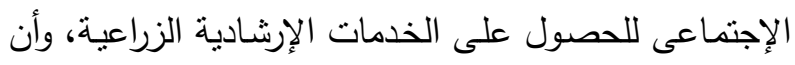
السلوك المتوقع لهؤلاء الزراع يتجه نحو استخدام تلك التهاع الوسائل

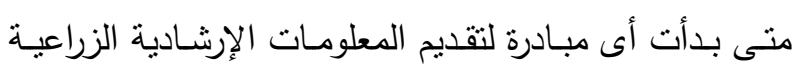
عن طريق تلك الوسائل، (عبد الغنى، 19 ـ ب). ونظرًا لكون أعضـاء مجالس إدارات الجمعيات التعاونيـة الزراعية هم قادة محليون، وهم الحلقة الوسيطة الهامة بين

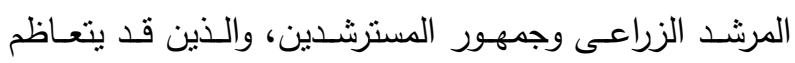

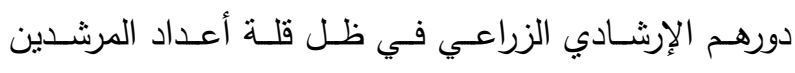

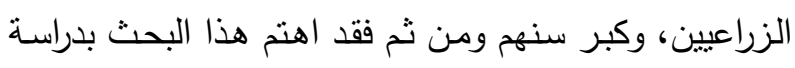

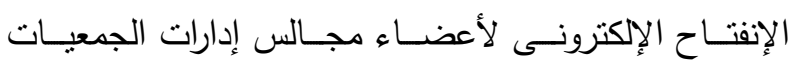

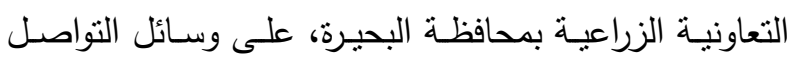

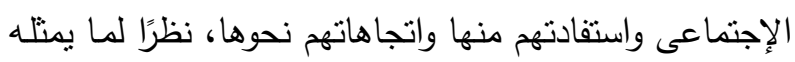

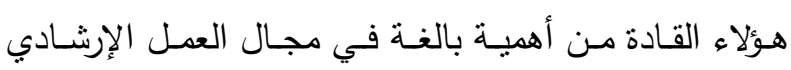

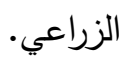

\section{الأهداف البحثية}

يستخهف هـذا البحـث بصـفة رئيسية، دراســة الإنفتـاح الإلكترونـي لأعضـاء مجــالس إدارات الجمعيـات التعاونيــة

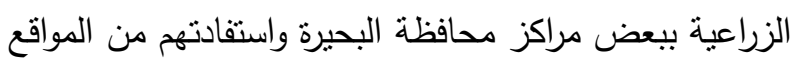

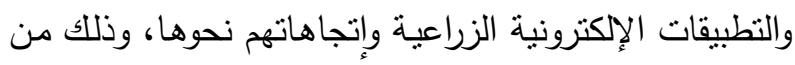
خلال تحقيق الأهداف الفرعية التالية:

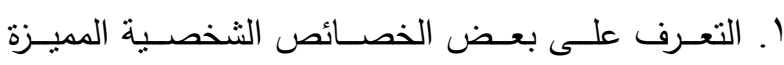
لأعضـاء مجـالس إدارات الجمعيـات التعاونيـة الزراعيـة

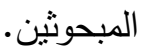
r. التعرف على درجة الإنفتاح الإلكتروني لأعضاء مجالس إدارات الجمعيات التعاونية الزراعية المبحوثين. 


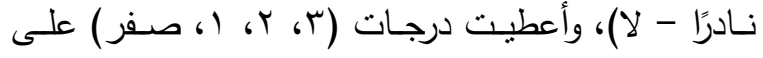
نفس التزتيب، ويتم التعبير عن ذلك بقيمة رقمية. (9) الاستعداد للتغيير : ويقصد بـه فى هذا البحث الموقف لفي السلوكى الذى يمكن أن يتخذه المبحوث عند السماع عن خمس توصـيات إرشــادية زراعيـة جديدة تتعلق بزراعـة محصول لم يسبق زراعته فى القرية، واستخدام مبيد جديد

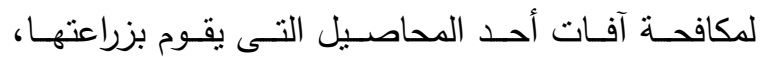
واسـتخدام المخلفــات الزراعيـة فـى عهـل أعـلاف غيـر تقليديـة، وتغييـر نظـام الـرى، والإعتمـاد على مصــادر جديدة للمعلومات الزراعية، ويتم التعبير عنه بقيمة رقمية يتم التوصل اليها من إجابات المبحوث على خمسة أسئلة وفقًا لمقياس رباعى متدرج من (أقوم بالتنفيذ فورًا، أنتظر حتى ينفذه البعض وينجح لديهم، أنتظر حتى ينفذه باقى الزراع فى القرية، لا أنف على الاطلاق) ويعطى المبحوث

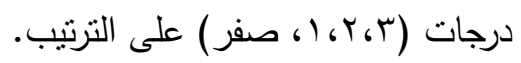
(·) (1) دافعية الإنجاز : ويقصد بها فى هذا البحث مدى موافقة

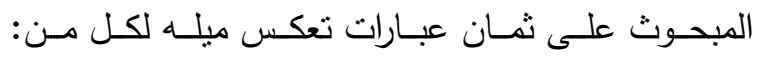
التخطيط للمستقبل، والإقبال على العمل، وعدم الخشية

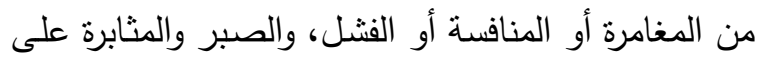
حل ما يواجهه من مشكلات، والرغبة في تأدية الأعمال التـي تتطلب مسـئولية كييـرة، وتحمـل مسئولية العـلـل، وتحقيق التميز عن باقى الزراع في القرية، وتقييم الأنثطة

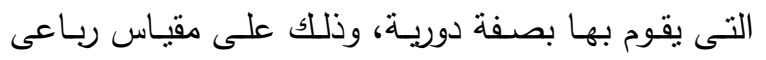
متدرج (دائمًا- أحيانًا- نادرًا - لا). وقد أعطيت درجات

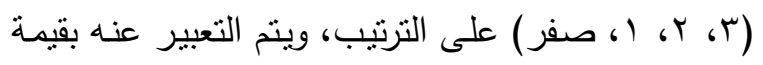

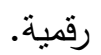
(1)(الإنفتاح الإكترونسي: ويقصد بـه في هذا البحث عدد

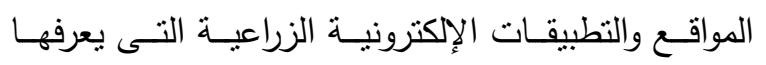

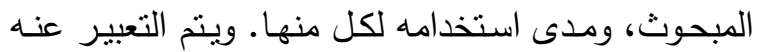

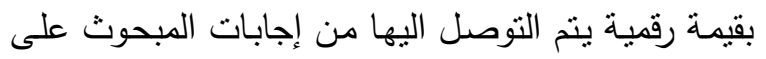

( ) المستوى التعليمى للأبناء: ويقصد به في هذا البحث

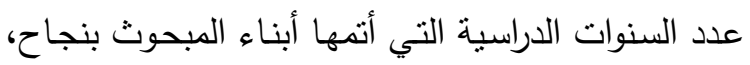
ويتم التعبير عنه بقيمة رقمية. (0) عدد أفراد الأسرة: ويقصد به فى هذا البحث عدد أفراد

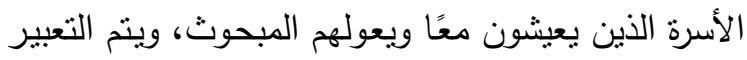
عنه بقيمة رقمية. (7) حبـازة الأرض الزياعيـة: ويقصـد بهـا في هذ البحث مجموع ما تحوزه أسرة المبحوث من أرض زراعية سواء كانت ملكًا أم إيجارًا أو مشاركة مقدرة بالقيراط. عضوية المنظمـات: ويقصد بها في هذا البحث مدى (V) مثـاركة المبحسوث فـي أنثـطة المنظمـات الاجتماعيـة والتعليمية والاقتصادية والسياسية القائمة بمنطقة البحث، مثل (الأحزاب السياسية، والمجلس المحلي، وجمعية تتمية المجتمع المحلى، ومجلس الآباء والمعلمين، ومجلس إدارة

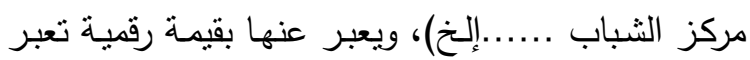
عن عدد المنظمات المشترك فيها، وطبيعة الدور الذي عيدي

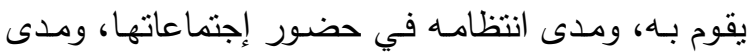

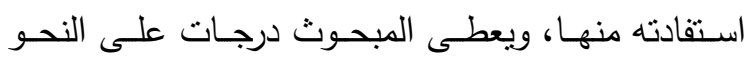

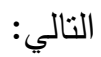
• العضـوية: رئيس مجلس إدارة (تلاث درجـات)، عضو مجلس ادارة (درجتان)، جمعيـة عموميـة (درجة واحدة)، ليس عضوًا (صفر).

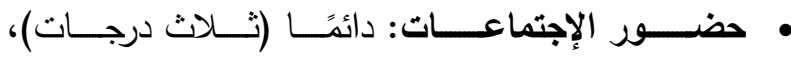
أحيانًا (درجتان)، نادرًا (درجة واحدة)، لا يحضر (صفر). • مــدى الاســتفادة: كبيـرة (تـلاث درجـات)، متوسـطة (درجتان)، محدودة (درجة واحدة)، منعدمة (صفر). (^) قيادة الزأى: ويقصد به في هذا البحث نقدير المبحوث

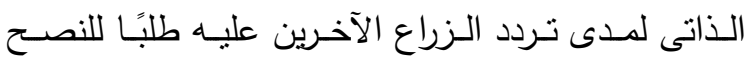
والمشورة فى ست موضوعات تتعلق بالنواحى الأسرية، والدينية، والزراعيـة، والسياسية، وخدمـة المجتمـع وتتميـة البيئة، وذللك على مقياس رباعى متدرج (دائمًا - أحيانًا - ولئية 
ودافعية الإنجاز ، والإتجاه نحو الإرشـاد الزراعي، والاستبصار الوجداني، والميل الاستثماري.

المتغيرات التابعة: وتتحصر في ثناث متغيرات هي: الإنفتاح

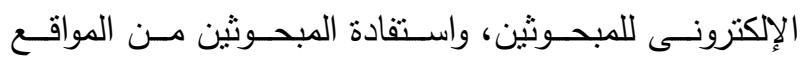
والتطبيقات الإلكترونيـة الزراعيـة، واتجاهـات المبحـوثين نحو المواقع والتطبيقات الإلكترونية الزراعية.

\section{ثالثًا: الفروض البحثية}

1 - تسـهم المتغيـرات المستقلة المدروسـة مجتمعـة فى تفسير التباين الكلى في درجـة الإنفتـاح الإلكتروني للمبحـثين كمتغير تابع.

r- تشـهم المتغيرات المستقلة المدروسـة مجتمعـة في تقسير التبـاين الكلى في درجـة اسـتفادة المبحوثين مـن المواقع والتطبيقات الإككترونية الزراعية كمتغير تابع. r- تسـهم المتغيرات المستقلة المدروسـة مجتمعـة في تفسير التباين الكلى في درجة اتجاهات المبحوثين نحو المواقع والتطبيقات الإلكترونية الزراعية كمتغير تابع. ك - يوجـد فـروق مغزويـة بـين المبحـوثين في مراكـز ايتـاى البارود وكفر الدوار ودمنهور من حيث درجة الإنفتاح

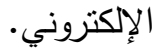

0- يوجـد فـروق مغزويـة بـين المبحـوثين في مراكـز ايتـاى

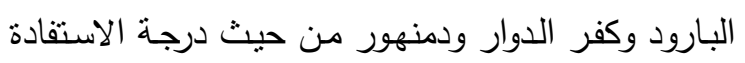

من المواقع والتطبيقات الإلكترونية الزراعية.

7- يوجـد فـروق مغزويـة بـين المبحـوثين في مراكـز ايتـاى البـارود وكفر الدوار ودمنهور مـن حيث درجـة الاتجـاه

نحو المواقع والنطبيقات الإلكترونية الزراعية.

رابعًا: الثاملة والعينة

تمثلت شاملة هذا البحث فى جميع أعضاء مجالس إدارات الجمعيات التعاونية الزراعية فى ثناثتة مراكز مختارة عشوائيًا

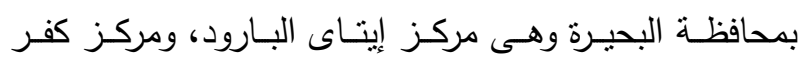

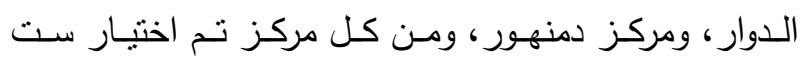

سؤالين يتعلقان بهذا الثأن، حيث يعطى المبحوث درجات على النحو التالى: - ع

المعرفـة بالوسـائل: يعطى المبحـوث درجـة واحده لكل وسيلة تواصل إجتماعي يذكرها.

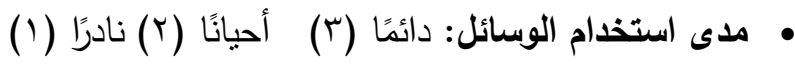
لا (صفر).

• الاستفادة من المواقع والتطبيقات الإكترونية الزراعية: ويقصد به فى هذا البحث عدد المجالات التي استفاد منها

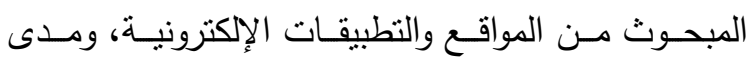
استفادته منها، ويتت التعبير عنه بقيمة رقمية يتم التوصل

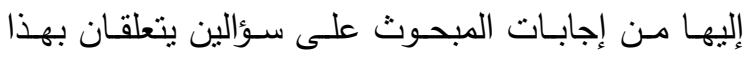
الثأن، ويعطى المبحوث درجات على النحو التالي: م مجـالات الاســفادة: يعطى المبحـوث درجـة واحده لكل

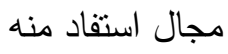

م مسـدى الاســفادة: كبيـرة (r) متوسـطة (Y) قليلـة (1) منعدمة (صفر).

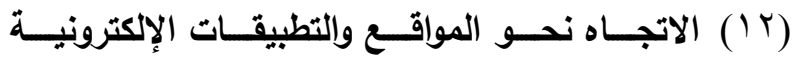
الزراعية: ويقصد به في هذا البحث موقف المبحوثين من حيث القبول أو المحايدة أو الرفض لمضدون • ب عبارة تتعلـق بـالمواقع والتطبيقـات الإلكترونيـة الزراعيـة، ويـتخ التعبيـر عن ذلـك بقيمـة رقميـة يـتم التوصـل اليهـا وفـق مقياس ثلاثي متدرج، حيث أعطى المبحوث درجات (Y، (Y) (، صـفر) وذلـك للعبـارات الإيجابيـة، و (صـفر، (، r) درجة للعبارات السلبية. ثانيًا: المتغيرات البحثية يتضمن هذا البحث نوعين من المتغيرات هما: المتغيرات المستقلة: وعددها (Y I) متغيرًا مستقلًا، وهم: سن المبحوثين، والمستوى التعليمى للمبحوثين، والمستوى التعليمى

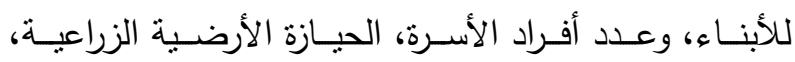

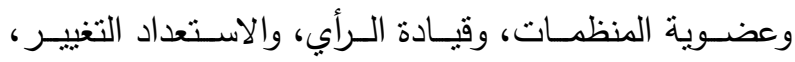


المبحوثين وفقًا لكل من تلك الخصـائص إستتادًا إلى قيم المتوسط الحسابى ونصف وحدة إنحراف معيارى إلى ثلاث

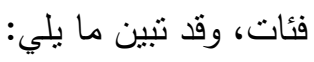

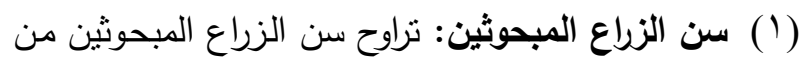

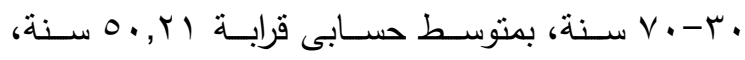

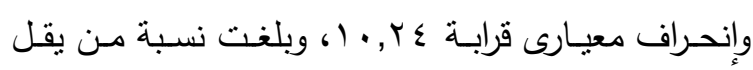

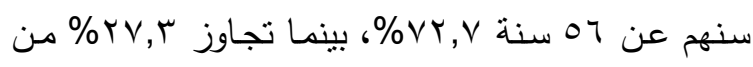

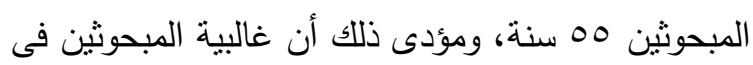

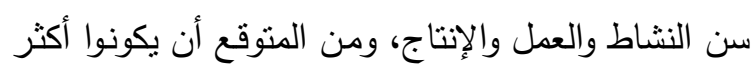

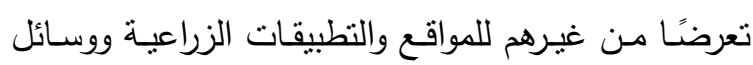
التواصل الاجتماعي، (جدول ()).

(r) المسـتوى التعليـــي للمبحــثين: تـراوح القيم الرقميـة

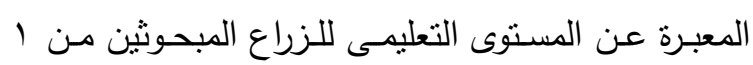

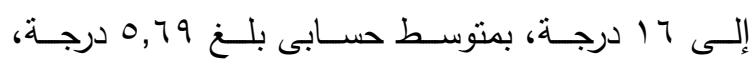

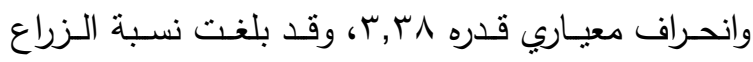

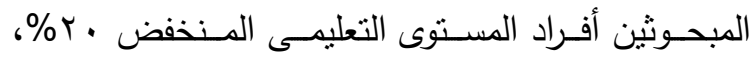

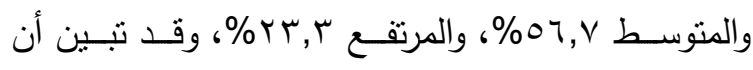

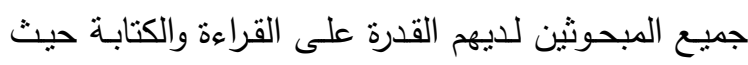

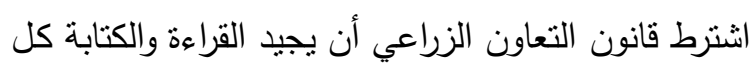

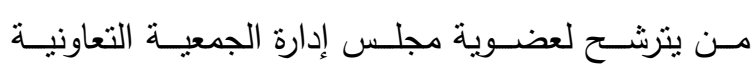
الزراعية، (جدول ()). المستوى التعليمى للأبناء: تزاوحت القيم الرقمية المعبرة

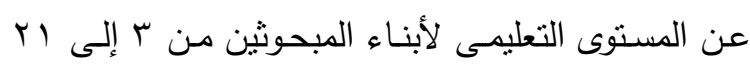

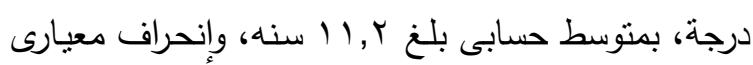

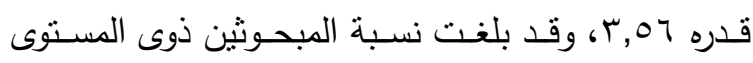

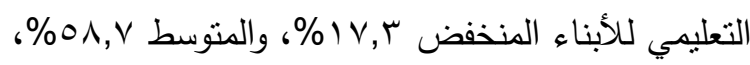

$$
\text { والمرتفع \&r\%، (جدول ()). }
$$

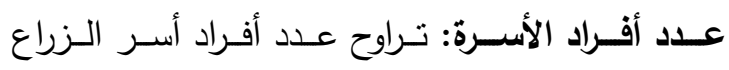

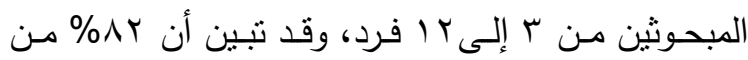
المبحوثين من ذوى الأسر منوسطة وقليلة العدد (ثمانية
جمعيات تعاونية زراعية بطريقة عشوائية، وهى: جمعيات: زهرة، والعكريثة، وكوم البركة، والعرقوب، والبسلقون، وبردلة من مركز كفر الدوار، وجمعيات: زرقون، ونديبة، ودنشال، ولئ، ودسونس، وشرنوب، وسنهور من مركز دمنهور ، وجمعيات:

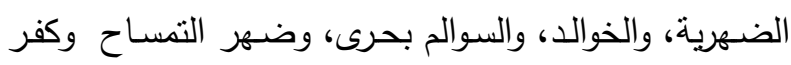

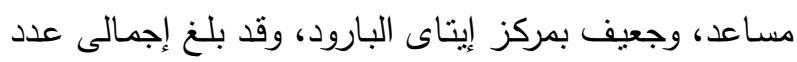
أعضاء مجالس إدارات الجمعيات التعاونية الزراعية الدختارة

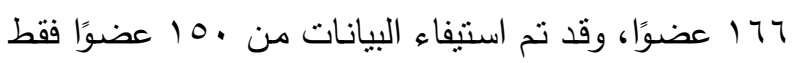

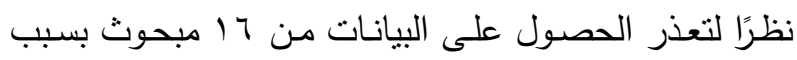

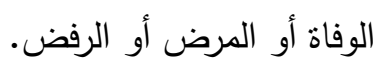
خامسًا: جمع وتحليل البيانات تم استيفاء البيانـات الميدانيـة باستخدام استمارة استيان

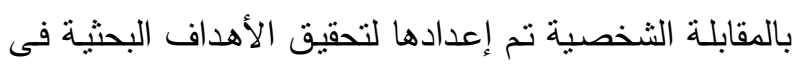

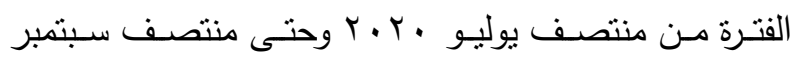

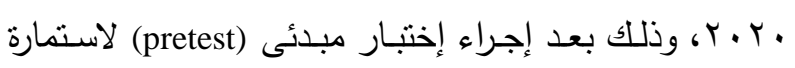
الاسنتيان مع 10 مبحوثًا من خارج عينة البحث، وذلك إنلك للنأكد

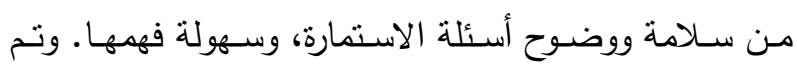

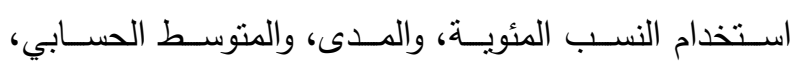

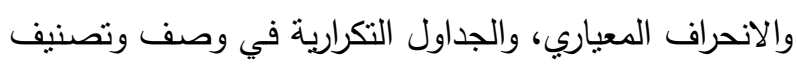

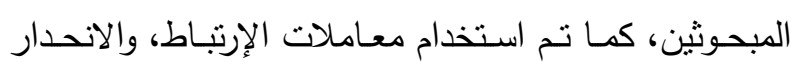
المتعدد فى التعرف على المتغيرات المستقلة المرتبطة والمؤثرة على المتغيرات التابعـة، كما استخدم إختبار نحليل التباين

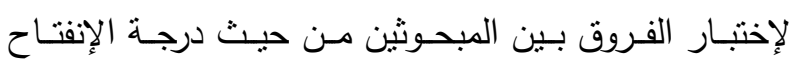

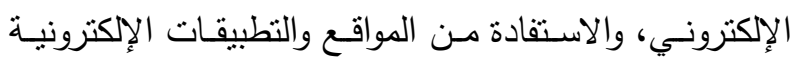

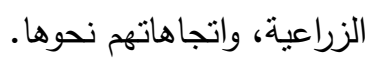

\section{النتائج البحثية}

أولا: الخصائص المميزة لأعضـاء مجـالس إدارات الجميـات

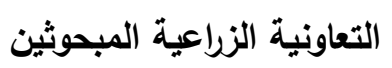

للتعرف على بعض الخصائص المميزة للزراع المبحوثين

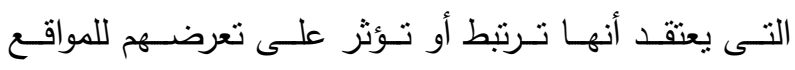

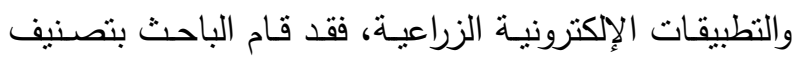


قيادة الرأي: تراوحت الدرجات المعبرة عن التقدير الذاتى (V)

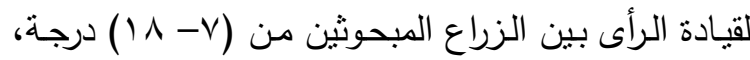

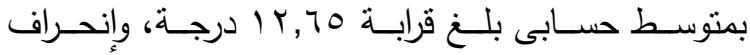

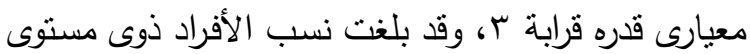

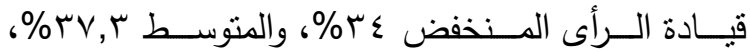
والمرتفع r Y,V\% من جملة المبحوثين، الأمر الذى يشير إلى أن مايزيد قليلاً على ربع المبحوثين (q ب \%) هم فقط

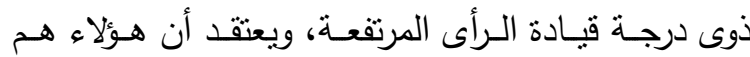
الأكثر تعرضًا واستفادة من المواقع والتطبيقات الاككترونية

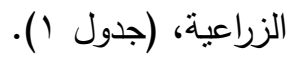

(^) الاسـتعداد للتغييـر : نراوحت القيم الرقميـة المعبرة عن الاستعداد للتغيير ببين الزراع المبحوثثن من (7- ع ( ) درجـة، بمتوسـط حسـابي قـدره ؟ب, • ا درجـة، وانحـراف معيـاري قدره قرابـة ا,Y، وقـد بلغـت نسـبة ذوى درجـة

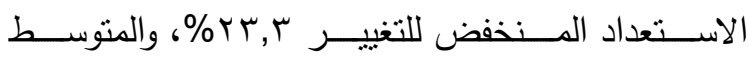

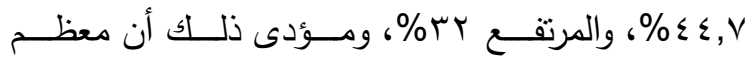

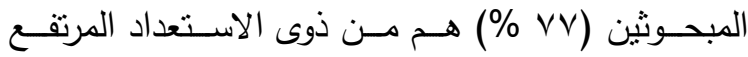
والمتوسط للتغيير وتبنى الأفكار الزراعية الجديدة، ويتفق ذللك مـع مـا أكدته الكتابات والدراسـات العلمية التي تؤكد أن القادة المحليين غالبًا ما يكونون أكثر استعدادًا للتغيير وتبنـى الأفكـار المسـتحدثة مقارنــة بغيـرهم مـن الـزراع،

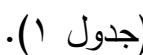

أفراد فأقل)، بينما بلغت نسبة من تجاوز عدد أفراد أسرهم ثمانية أفراد ^/ ( ) فقط من جملة المبحوثين، (جدول ( ). (0) الحيـازة الأرضـية الزراعيـة: نراوحت الحيازة الأرضية

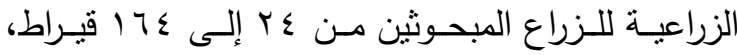
بمنوسط حيازة قدره V ₹, ד 7 قيراط، وإنحراف معيارى بلغ

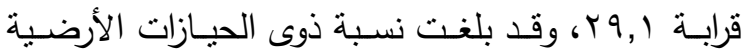

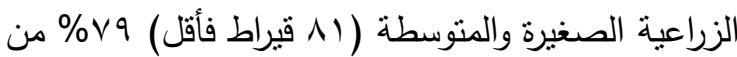
جملـة الـزراع المبحـوثين، فـى حـين بلغــت نسـبة ذوى الحيازات الأرضية الكبيرة ابY\% من المبحوثين، ويعتقد أن ذوى الحيازات الكبيرة أكثر تعرضًا واستفادة من المواقع والتطبيقات الالكترونيـة الزراعيـة مقارنــة بـذى الحيـازات الصغيرة والمتوسطة، وذللك حرصًا منهم للسعى للحصول على كل مـاهو جديـد ومفيد مـن المعلومـات مـن شـتى مصادرها لصالح المزرعة والإنتاج، (جدول ( ). (T) عضــوية المنظمــات : تراوحت الـدرجات المعبـرة عـن عضـوية الـزراع المبحـوثين فـى المنظمـات القائمـة فـى

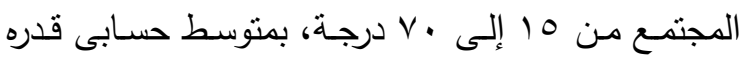

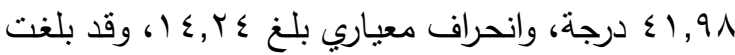
نسـبة ذوى الدرجـة المنخفضـة في عضــية المنظمـات

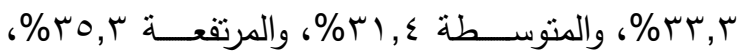
الأمر الذي يشير إلى أن حوالى ثلث المبحوثين فقط هم

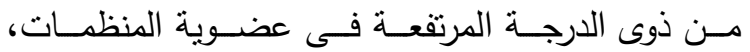
والمتوقع أن يكون هؤلاء المبحوثين أكثر تعرضًا واستفادة من المواقع والتطبيقات الاككترونية الزراعية، (جدول (). 
جدول 1. توزيع أعضاء مجالس إدارات الجمعيات التعاونية الزراعية المبحوثين وفقا للخصائص المميزة لهم

\begin{tabular}{|c|c|c|c|c|c|}
\hline$\%$ & العدد & الخصائص & $\%$ & العدد & الخصائص \\
\hline & & قيادة الرأي (درجة) & & & سن المبحوثين (سنة) \\
\hline$r \varepsilon$ & 01 & منخفض (أقل من ( ) & rr & $\varepsilon \wedge$ & صغير (أقل من 0؛) \\
\hline$r \vee, r$ & 07 & متوسط (ع 1-11) & $\varepsilon,, v$ & 71 & منوسط (0؛ -00) \\
\hline \multirow[t]{2}{*}{$r \wedge, \vee$} & $\varepsilon r$ & مرتفع (أكبر من ء () & $r V, r$ & $\varepsilon$ & كبير (أكبر من 00) \\
\hline & & الاستعداد للتغيير (درجة) & & & المستوى التعليمي للمبحوثين (درجة) \\
\hline r & ro & قليل (أقل من 9) & r. & r. & صغير (أقل من "r) \\
\hline$\varepsilon \varepsilon, V$ & TV & متوسط (9 - 1 (1) & $07, \mathrm{~V}$ & 10 & متوسط (r - £) \\
\hline \multirow[t]{2}{*}{ rr } & $\varepsilon \wedge$ & كبير (أكبر من ا') & $r$ & ro & كبير (أكبر من \&) \\
\hline & & دافعية الإنجاز (درجة) & & & المستوى التعليمي للأبناء (درجة) \\
\hline r^,〉 & $\varepsilon r$ & منخفض (أقل من 7 ( ) & IV,r & r & صغير (أقل من 9) أ) \\
\hline$\varepsilon V, r$ & v) & متوسط (T/-17) & $\Delta \wedge, \mathrm{V}$ & $\Lambda \Lambda$ & منوسط (q- (1) \\
\hline \multirow[t]{2}{*}{$T \leq$} & צי & مرتقع (أكثر من ·r) & $r \varepsilon$ & 4ו & كبير (أكبر من َا) \\
\hline & & الاتجاه نحو الإرشاد الزراعى (درجة) & & & عدد أفراد الأسرة (فرد) \\
\hline ז & 00 & سلبي (اقل من آس) & rی & $\varepsilon r$ & صغيرة (أقل من ؟) \\
\hline$\Gamma \varepsilon$ & 01 & محايد (1/ - דr) & $0 \leqslant$ & (1) & متوسطة (^-1) \\
\hline \multirow[t]{2}{*}{ r৭, } & $\leqslant \varepsilon$ & إيجابي (أكبر من דَr) & 11 & tr & كبيرة (أكبر من ^) \\
\hline & & الاستبصار الوجدانى (درجة) & & & الحيازة الأرضية الزراعية (فدان) \\
\hline$r$. & $r$. & سلبي (اقل من · 1) & $\leqslant r, \varepsilon$ & 70 & صغيرة (أقل من 10) \\
\hline$\sum 7$ & 79 & محايد (·1 - r & ro,r & or & متوسطة (1)-10) \\
\hline \multirow[t]{2}{*}{$r \varepsilon$} & 01 & إيجابي (أكبر من ஈ 1 ) & $r, r$ & rr & كبيرة (أكبر من (^) \\
\hline & & الديل الاستثمارى (درجة) & & & عضوية الدنظمات (درجة) \\
\hline$r \varepsilon$ & ד & قليل (أقل من \) & r & 0. & منخفض (أقل من مr) \\
\hline$\varepsilon 9, r$ & $V \varepsilon$ & 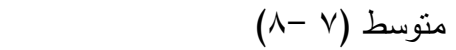 & $\Gamma_{1, \varepsilon}$ & $\leqslant v$ & متوسط (0) - ؟ ؟) \\
\hline 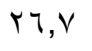 & $\varepsilon$. & كبير (أكبر من ^) & ro,r & or & مرتفع (أكبر من 9 §) \\
\hline
\end{tabular}

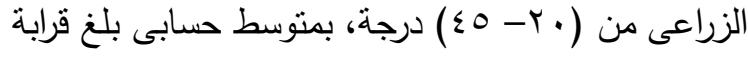

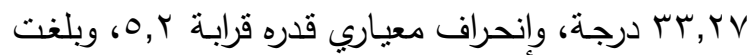

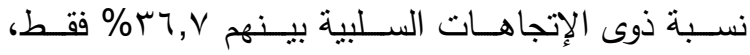

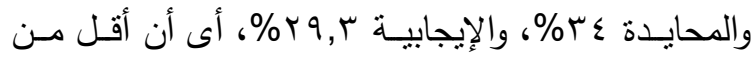

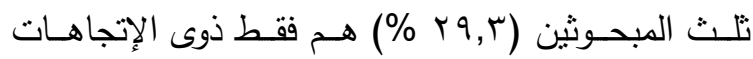

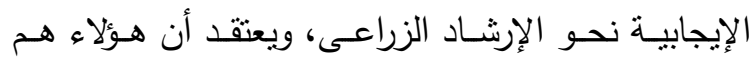

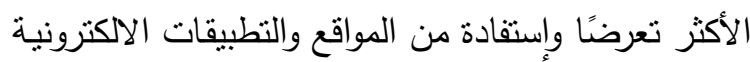

$$
\text { الزراعية، (جدول ()). }
$$

(1' (1) الاستبصار الوجداني: تزاوحت القيم الرقمية المعبرة عن

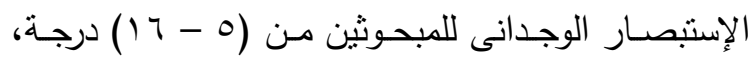
بمنوسط حسابي بلغ قرابة V, 11 الئة درجة، وانحراف معياري
(9) دافعيـة الإنجاز : نزاوحت الدرجات المعبرة عن دافعية

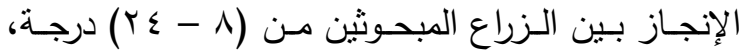
بمتوسط حسابى بلغ قرابة V V,A درجة، وإنحراف معيارى

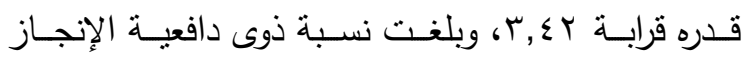

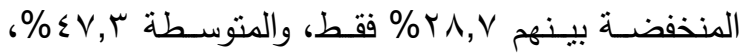

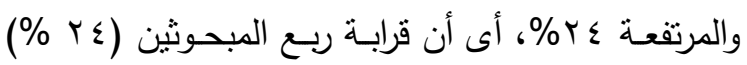
هم فقط ذوى دافعيـة الإنجاز المرتفعة، ويعتقد أن هؤلاء

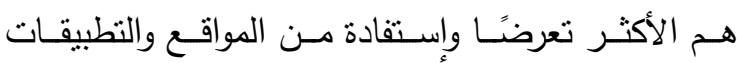

$$
\text { الالكترونية الزراعية، (جدول ()). }
$$

(·) (1) الاتجاه نحو الإششـاد الزراعي: تراوحت القيم الرقمية

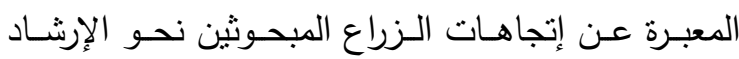


مصطفي صبري مصطفى صالح وأخرون.،: الإنفتاح الإكتروني لأعضاء مجالس إدارات الجمعيات التعاونية الزراعية ...

الى ثلاث فئات، فقد بلغت نسبة أفراد مستوى الإنفتاح

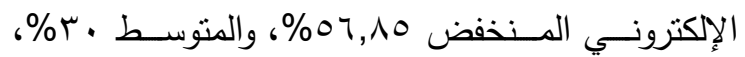

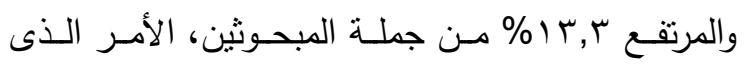

يشير إلى تدنى نسبة المبحوثنين ذوى الإنفتاح الإلكتروني

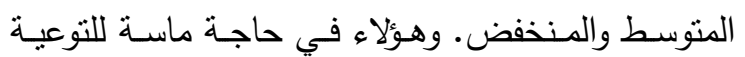

بالمواقع والتطبيقات الالكترونية الزراعية، (جدول r r).

جدول r . توزيع المبحوثين وفقا لفئات الإنفتاح الإكتروني

\begin{tabular}{|c|c|c|}
\hline النسبة المئوية & العدد & فئات الإنفتاح الإلكتروني (درجة) \\
\hline $07, V$ & 10 & منخفض (أقل من 10) \\
\hline$r$ & 纟o & متوسط (10 - سr) \\
\hline ז & r. & مرتفع (أكثر من rr) \\
\hline $1 \cdots$ & 10. & المجموع \\
\hline
\end{tabular}

ولمزيد من الإيضاح فقد نبين ما يلي:

(1) معرفــة المبحـوثين بـالمواقع والتطبيقــات الالكترونيـة

الزراعية: تراوحت القيم الرقمية المعبرة عن عدد المواقع

والتطبيقات الاككترونيـة الزراعيـة التى يعرفها المبحوثين من صفر إلى • 1 درجات بمتوسط حسابي قدره 09, ؛

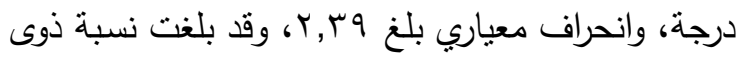

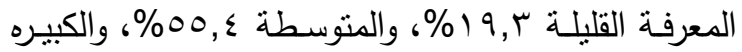

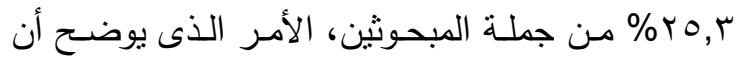
قرابة ربع المبحوثين فقط هم الذين يعرفون عددًا كبيرًا من المواقع والتطبيقات الالكترونية الزراعية، بينما يقع غالبية المبحوثين في فئتي المعرفـة المتوسطة والقليلة، وهؤلاء فـي حاجـة ماسـة للتوعيـة بكيفيـة التعامـل مـع المواقـع

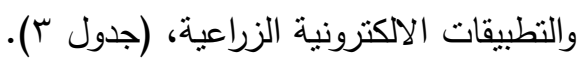

جدول ب. توزيع الزراع المبحوثين وفقًا لفئـات عدد المواقع والتطبيقات الاكترونية الزراعية التي أفادوا بمعرفتها

\begin{tabular}{|c|c|c|}
\hline النسبة المئوية & العدد & الفئات (درجة) \\
\hline $19, r$ & $r q$ & منخفض (أقل من r) \\
\hline $00, \varepsilon$ & r & متوسط (r - ؟) \\
\hline$r 0, r$ & r人 & مرتفع (أكثر من ج') \\
\hline $1 \ldots$ & 10. & المجموع \\
\hline
\end{tabular}

قدره قرابـة ^, ץ، وبلغت نسبة ذوى الاستبصـار الوجدانى

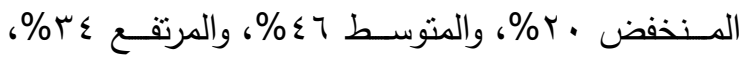
الأمـر الـي يؤكد أن معظم المبحـوثين مـن ذوى درجـة الاستبصار الوجداني المرتفع والمتوسط، (جدول ()). (r ( ) الميل الاستثماري: تراوحت الدرجات المعبرة عن الميل الإستثمارى للمبحوثين من (r - • 1 ) درجات، بمتوسط حسابى بلغ قرابة ؟ ₹, درجة، وإنحراف معياري قدره قرابة

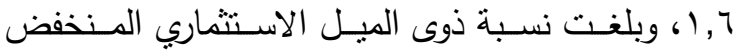
\&

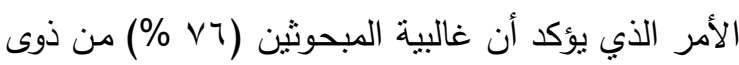
درجة الميل الاستثماري المرتفع والمتوسط، (جدول ()). ثانيًا: معسارف وخبـرات أعضـاء مجـالس إدارات الجمعيـات التعاونيـة الزراعيـة المبحوثين عن المواقـع والتطبيقـات الإلكترونية الزراعية

(1) توفر خلمـة الإنترنت : أفاد جميع المبحوثين بأن خدمة

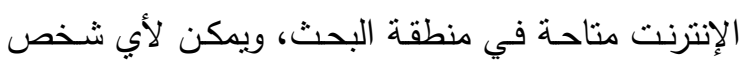
في المنطقة الاشـتراك فيها سـواء على هاتقـه المحمـول الذي بـه إمكانيـة ذلك أو هاتفهـ المنزلي، كمـا أفاد جميع المبحوثثن باستفادتهم من خدمة الإنترنت.

(ץ) حيـازة الهاتف المحمـول: أفاد جميع المبحوثين بـأنهم يحوزون هم أو أحد أفراد أسرهم هاتفا محمولًا، وأن أغلب هذه الهواتف مزود بإمكانية الاتصال بالإنترنت.

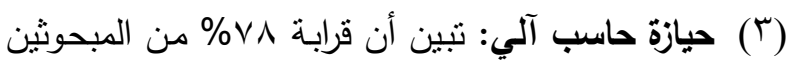

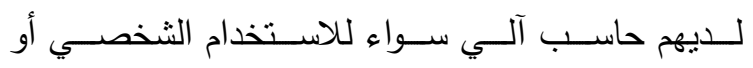
الاستخدام العائلي.

(ع) الإنفتاح الإلكتروني للمبحوثين: أظهرث النتائج البحثية

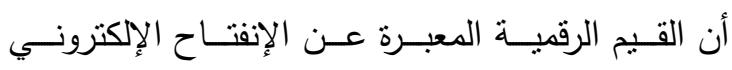
للمبحوثين قد تراوحت من صفر إلى هب درجة، بمتوسط الزي

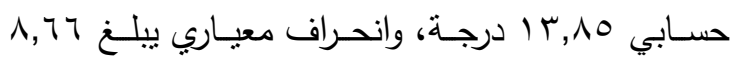
درجة، وبتصنيف المبحوثين وفقًا لقيمهم الرقمية إستتادًا إلى قيم المنوسط الحسابى ونصف وحدة إنحراف معيارى 
جدول ؛ ـ توزيـع الزراع المبحوثين وفقًا لفئـات استخدامهم

للمواقع والتطبيقات الاكترونية الزراعية

\begin{tabular}{|c|c|c|}
\hline النسبة المئوية & 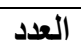 & فئات مستوى الاستخدام (درجة) \\
\hline $19, r$ & rq & منخفض (أقل من r) \\
\hline $00, \Sigma$ & NT & متوسط (T - T) \\
\hline$r 0, r$ & rᄉ & مرتفع (أكثر من 7) \\
\hline $1 \ldots$ & 10. & المجموع \\
\hline
\end{tabular}

ولمزيــد مـن الإيضـاح فقد تم ترتيب المواقع والتطبيقات

الالكترونية الزراعية وفقًا لدرجة الإنفتاح الإلكترونى على كل الإبل

منها (مجموع درجتى السماع والاستخدام) على النحو المبين

(r) اسـتخدام المبحــثين للمواقـع والتطبيقـات الاكترونيـة

الزراعيـة: تراوحت القيم الرقميـة المعبـرة عن استخدام

المبحوثين للمواقع والتطبيقات الالكترونيـة الزراعيـة من

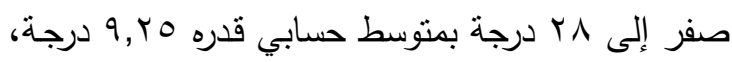

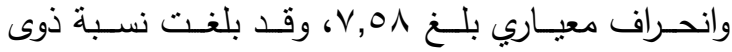

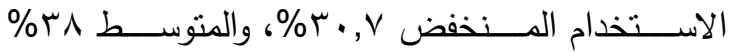

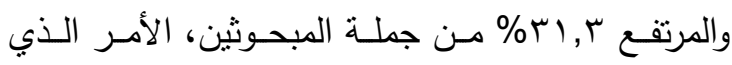

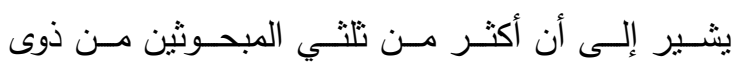

الاســتخدام المـنـفضض والمتوســط للمواقـع والتطبيقـات

الالكترونية الزراعية، (جدول ؟).

جدول ه. ترتيب المواقع والتطبيقات الاكترونية الزراعية وفقًا لارجة سماع المبحوثين عن كل منها، ومدى استخدامهم لها

\begin{tabular}{|c|c|c|c|c|c|c|c|}
\hline \multirow{2}{*}{ الإنفتاح } & \multicolumn{4}{|c|}{ مدى الاستخدام } & \multicolumn{2}{|l|}{ السماع } & \multirow{2}{*}{ المواقع والتطبيقات الاكترونية الزراعية } \\
\hline & ע & نادراً & أحياناً & دائماً & لم يسبق له السماع & سمع & \\
\hline$r q$. & 9 & $\wedge$ & 10 & $\wedge$. & $r \wedge$ & $11 r$ & فيس بوك \\
\hline אמr & 9 & . & $r$. & 77 & 00 & 90 & موقع مديرية الزراعة بمحافظة البحيرة \\
\hline$r \varepsilon \varepsilon$ & r & $\wedge$ & $1 \leq$ & $\leqslant 7$ & $\Lambda$. & $\vee$. & واتساب \\
\hline $1 \wedge \varepsilon$ & r. & 0 & 1. & r & $\Lambda \varepsilon$ & 77 & موقع عالم الزراعة \\
\hline r & r & $\wedge$ & 7 & $r \varepsilon$ & 11. & $\varepsilon$. & دليل المبيدات \\
\hline$|r|$ & 17 & 9 & 9 & 10 & 1.1 & $\leq 9$ & السوق الزراعي \\
\hline 97 & 1. & r & $\wedge$ & $1 \leq$ & 110 & ro & تطبيق إروى \\
\hline 19 & V & 0 & - & 11 & Ir. & r. & موقع وزارة الزراعية \\
\hline 91 & $\checkmark$ & 1. & - & 17 & $11 \mathrm{~V}$ & r & منتدى الخيرات الزراعية \\
\hline v) & $\varepsilon$ & 7 & 0 & 1. & ro & ro & بوابات كنانة أونلاين. . \\
\hline 77 & $v$ & $\varepsilon$ & 0 & 9 & ro & ro & المعمل المركزى للنظم الخبيرة \\
\hline $7 \varepsilon$ & $\wedge$ & 0 & r & 1. & iro & ro & دليلك الزراعي \\
\hline$\varepsilon 9$ & 0 & r & r & $\wedge$ & Tr & 11 & منتدى زراعةً نت \\
\hline$\varepsilon 9$ & 1. & 0 & r & 0 & ITV & r & خيرات بلدنا \\
\hline$\varepsilon q$ & 1. & 0 & r & 0 & ITV & r & موقع خيرات بلدنا \\
\hline ¿0 & 0 & $\varepsilon$ & . & $\wedge$ & 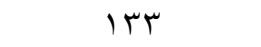 & iv & بشاير \\
\hline iv & . & . & r & r & $1 \leqslant 0$ & 0 & انستجرام \\
\hline 17 & $\wedge$ & . & . & r & $1 \varepsilon$. & 1. & المنصة الزراعية الإكترونية \\
\hline $1 \varepsilon$ & r & r & 1 & 1 & $1 \leqslant r$ & 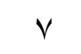 & الساقية للتمية الزراعية \\
\hline 0 & r & . & 1 & . & $1 \leqslant V$ & r & بلانتكس \\
\hline
\end{tabular}


شراء مستلزمات الانتاج الزراعي، ومجال تسهيل الوصول إلى التجار والموزعين، ومجال معرفة آفات المحاصيل والطرق الصحيحة لمقاومتها في مؤخرة تلك القائمة.

(7) آجاهات المبحوثين نحو المواقع والتطبيقات الاكترونية

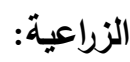

تراوحـت القيم الرقميــة المعبـرة عـن اتجاهـات الـزراع

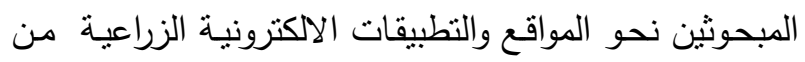

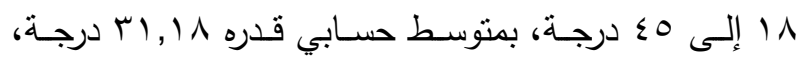

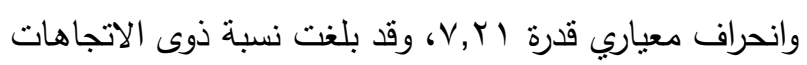

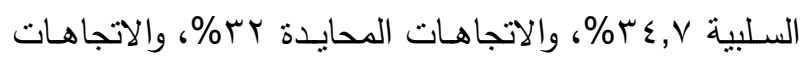

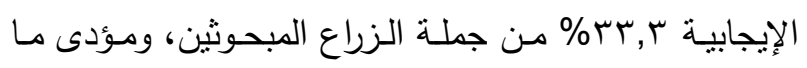

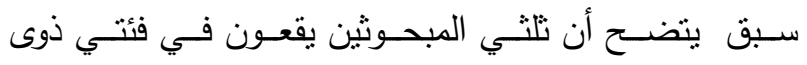

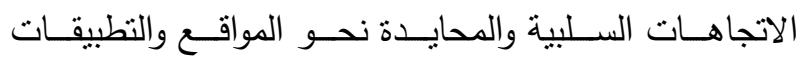
الالكترونية الزراعية، بينما تتسم اتجاهات ثلث المبحوثين فقط

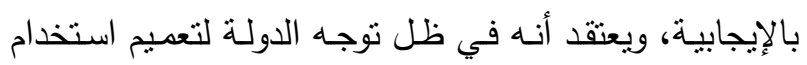
شبكة الانترنت في جميع أجزاتها وتحديث النظم المنبعة في

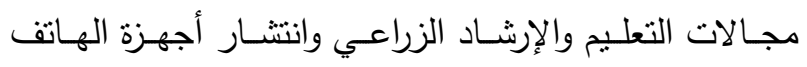

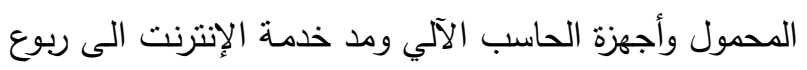
مصر فسوف تزداد اعداد المعتمدين على وسائل التواصل الإجتماعى كمصادر مرجعية هامة تحظى بثقة الزراع وقادتهم

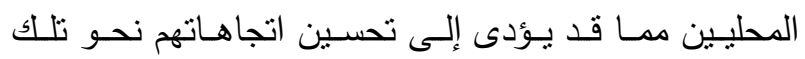

$$
\text { الوسائل، (جدول ^). }
$$

ثالثًا: العلاقات التأثيرية بين المتفيرات المستقلة وكل من

$$
\text { المتغيرات التابعة }
$$

أمكن دراسـة العلاقة الإرتباطية بين كل من المتغيرات

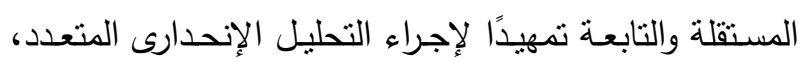

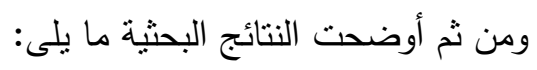

ومـن ثم فقد تبين أن الفيس بـوك، وموقع مديريـة الزراعـة

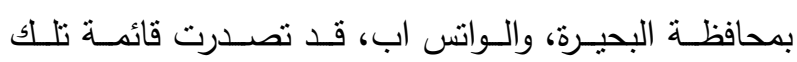
الوسائل، بينما جاء في مركز متوسط موقع عالم الزراعة،

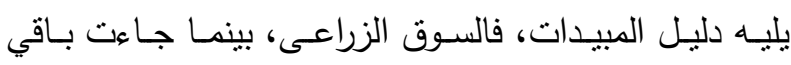
الوسائل في مؤخرة تلك القائمة، (جدول ه).

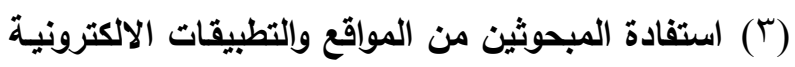

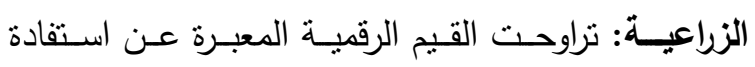

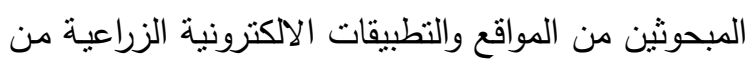

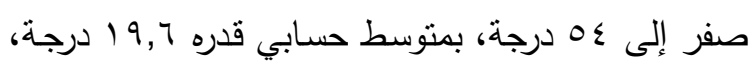
وانحراف معياري قدرة 10، وقد بلغت نسبة ذوى الاستفادة

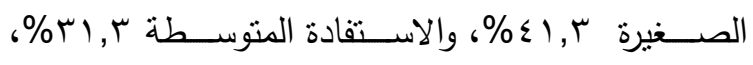

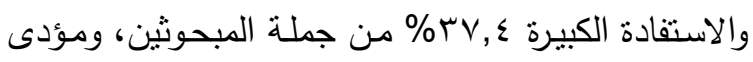

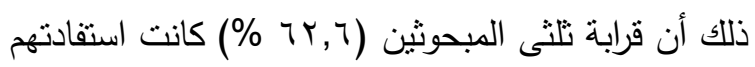

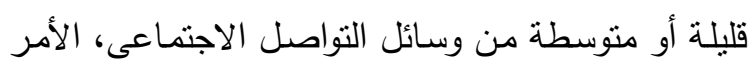

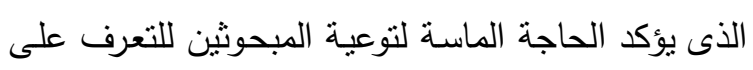

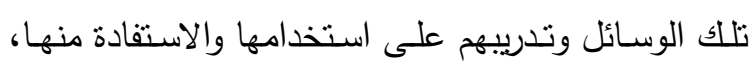

\begin{tabular}{|c|c|c|}
\hline & إعية & مواقع والتطبيقات الاككن \\
\hline النسبة المئوية & العدد | - العد & فئات الاستفادة (درجة) \\
\hline$r, r$ & $\varepsilon V$ & قليلة (أقل من r I) \\
\hline M, r & $\varepsilon V$ & متوسطة (YV - TV \\
\hline$r v, \varepsilon$ & 07 & كبيرة (أكثر من YV) \\
\hline $1 \ldots$ & 10. & المجموع \\
\hline
\end{tabular}
(جدول r).

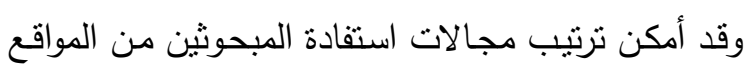

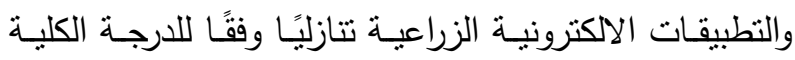

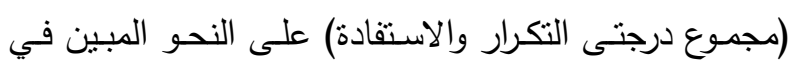

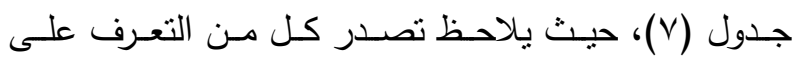

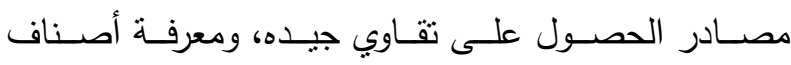

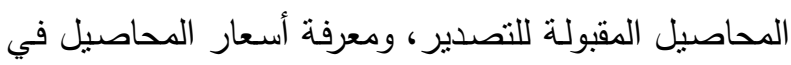
البورصة العالمية، قائمة مجالات الاستفادة بينما جاء مجال 
جدول v. مجالات الاستفادة من المواقع والتطبيقات الاكترونية الزراعية

\begin{tabular}{|c|c|c|c|c|c|c|c|c|c|}
\hline \multicolumn{7}{|c|}{ مدى الاستفادة } & \multirow{3}{*}{$\%$} & \multirow{3}{*}{ 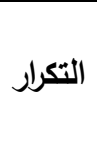 } & \multirow{3}{*}{ مجالات الاستفادة الاد } \\
\hline \multirow{2}{*}{ 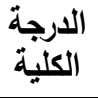 } & \multicolumn{2}{|c|}{ قليلة } & \multicolumn{2}{|c|}{ متوسطة } & \multicolumn{2}{|c|}{ كبيرة } & & & \\
\hline & $\%$ & عدد & $\%$ & عدد & $\%$ & عدد & & & \\
\hline$r \leq 0$ & $r, r$ & 0 & 17,7 & ro & $r \uparrow, \uparrow$ & $\varepsilon \cdot$ & $\leq 7,7$ & $\vee \cdot$ & جيده. \\
\hline TrY & $9, r$ & $1 \leqslant$ & ir & 11 & $r \mu, r$ & ro & $\varepsilon \varepsilon, 7$ & TV & تسهيل الوصول إلى التجار والموزعين \\
\hline$r \leqslant r$ & $\varepsilon$ & 7 & 7,7 & $1 \cdot$ & $r \mu, r$ & 0. & $\varepsilon \varepsilon$ & 77 & 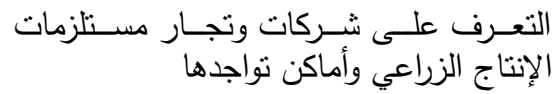 \\
\hline rro & $r, r$ & 0 & 17,7 & ro & $r$ r & ro & $\varepsilon r, \Gamma$ & 70 & معرفة أصناف المحاصيل المقبولة للتصدير \\
\hline rrq & $1, r$ & r & 1. & 10 & $r$. & $\leqslant 0$ & $\varepsilon 1, r$ & Tr & الجديدة للمحاصيل الظـروف المختلفي لزراعـة الأصـــاف \\
\hline$r . q$ & & & $10, r$ & $r T$ & $r r, r$ & ro & $\lceil\wedge, \uparrow$ & 01 & المحرفيل أسـعار مستلزمات الإنتاج في السـوق \\
\hline 190 & $1, r$ & $r$ & $1 \varepsilon$ & $\langle 1$ & $r, r$ & rr & ד & 00 & اللازمة لزراعة كمية التقاوى من الميفة تجهيزها للزراعة المختلفة \\
\hline $17 r$ & 7,7 & 1. & Ir & 11 & $1 \leqslant, 7$ & rr & r, & 0 . & المحلى أسعار المحاصيل الزراعية في السوق \\
\hline $10 \mathrm{~V}$ & $v, r$ & 11 & $r, r$ & 0 & $r$. & $r$. & $r \cdot, \tau$ & $\leqslant 7$ & المختلفة أفضــل الأسـواق لتصـــر المحاصـيل \\
\hline ITV & $11, r$ & IV & $M, T$ & 19 & 7 & 9 & $r$. & $\leqslant 0$ & لمقاومتهـا آفـات المحاصـيل والطـرق الصـــيحة \\
\hline $17 \varepsilon$ & & & $r, T$ & $\varepsilon$ & $r_{0, r}$ & rᄉ & rᄉ & $\varepsilon r$ & معرفة الطرق الصحيحة لتخزين التقاوى \\
\hline $1 \varepsilon$. & $r, r$ & 0 & 7,7 & $1 \cdot$ & 17,7 & ro & $r\urcorner\urcorner$, & $\varepsilon \cdot$ & المختزفة عمليـات مــا بعـد حصــاد المحاصـيل \\
\hline $11 \leq$ & $\cdot, 7$ & 1 & $r, r$ & $\varepsilon$ & 17,7 & ro & $r \cdot$ & $r \cdot$ & وتحديد درجة الأماكن المختلفة لتحليل التربة الزراعية \\
\hline $1 \cdot 1$ & $1, r$ & r & $0, r$ & $\wedge$ & $14, r$ & r. & r. & $r \cdot$ & تسويق المحاصيل المختلفة. \\
\hline 19 & $\Lambda, \uparrow$ & IT & $r, r$ & 0 & $\wedge$ & IT & $r \cdot$ & $r \cdot$ & معرفة كيفية تجهيز الأرض وإعدادها للزراعة \\
\hline 10 & $1 \cdot$ & 10 & $r, r$ & $\circ$ & 7,7 & $1 \cdot$ & $r \cdot$ & $r \cdot$ & شراء مستلزمات الانتاج الزراعي \\
\hline$\wedge \varepsilon$ & $9, r$ & $1 \varepsilon$ & $0, r$ & $\wedge$ & $0, r$ & $\wedge$ & $r$. & $r$. & وتوقيتاتها المثلى . معلى الزراعية لمختلف المحاصيل \\
\hline$\vee \wedge$ & سז, 11 & IV & $0, \pi T$ & $\wedge$ & $\Gamma, r$ & 0 & $r$. & $r$. & 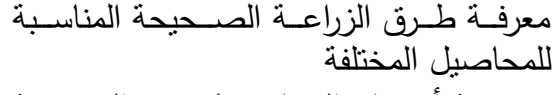 \\
\hline 77 & r & $r$ & & & 1. & 10 & IT & 11 & العالمرفية أســعار المحاصـيل فــي البورصــة \\
\hline
\end{tabular}

جدول ^. توزيع الزراع المبحوثين وفقًا لفئات اتجاهاتهم نحو المواقع والتطبيقات الاكتترونية الزراعية

\begin{tabular}{|c|c|c|}
\hline النسبة المئوية & العدد & فئات الإتجاه (درجة) \\
\hline$r \varepsilon, V$ & or & سلبي (أقل من Y^) \\
\hline rr & $\varepsilon \wedge$ & محايد (r \\
\hline 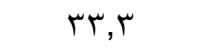 & 0. & إيجابي (أكثر من ro) \\
\hline $1 \ldots$ & 10. & المجموع \\
\hline
\end{tabular}




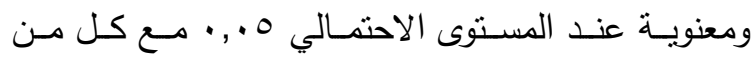
متغيري قيادة الرأي، والاستعداد للتغيير ، وكانت العلاقة التحة

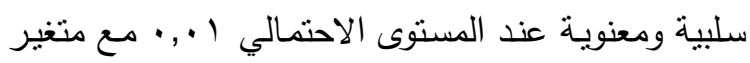

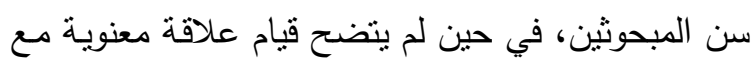

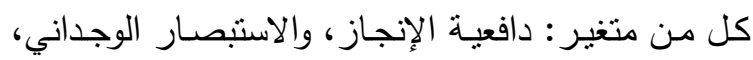

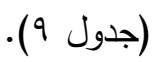

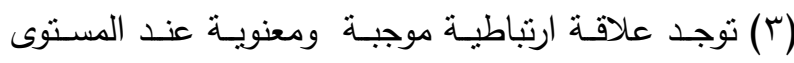

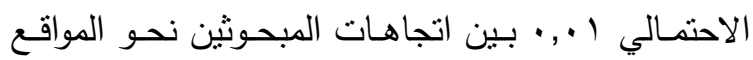

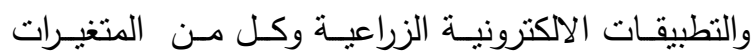

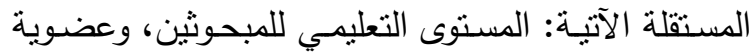

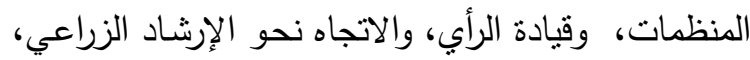

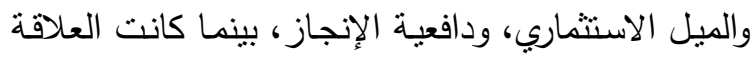

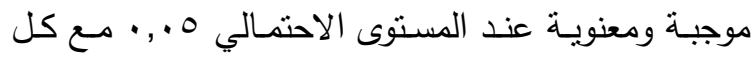

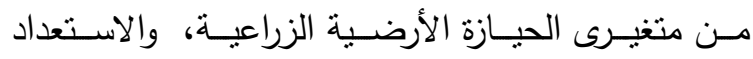

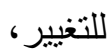

(1) توجد علاقـة ارتباطيـة موجبـة ومعنويـة عند المستوى المئ الاحتمالي ا .,. بين الإنفتاح الإلكتروني للمبحوثين وكل

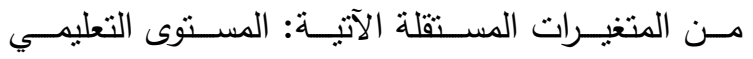

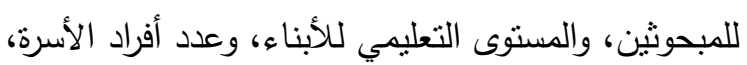

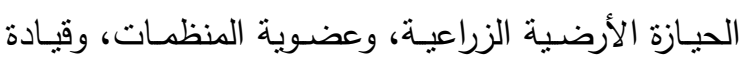

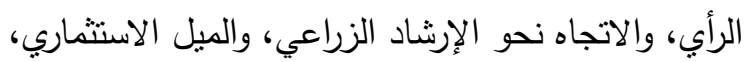

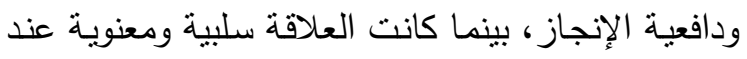

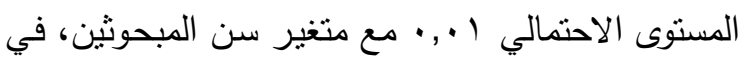

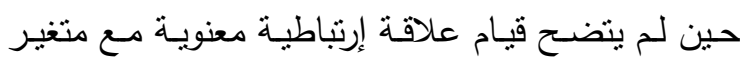

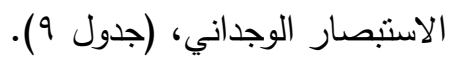

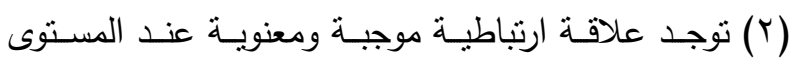

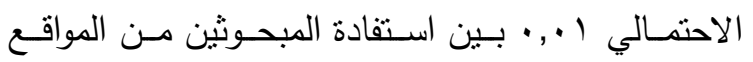

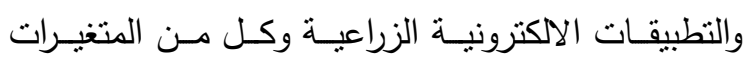

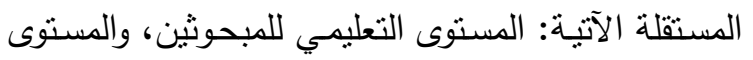

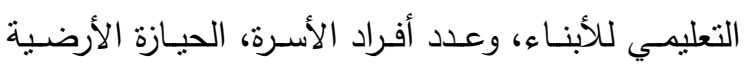

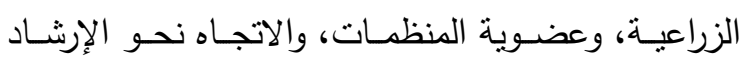

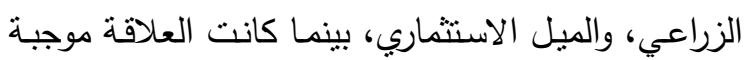

جدول 9.

\begin{tabular}{|c|c|c|c|}
\hline \multicolumn{3}{|c|}{ المتغيرات التابعة } & \multirow{3}{*}{ المتغيرات المستقلة } \\
\hline الإتجاه & الاستفادة & الانفتاح الإلكتروني & \\
\hline معامل الارتباط & معامل الارتباط & معامل الإرتباط & \\
\hline$* * \cdot, 0 \wedge r-$ & ***, & 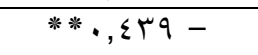 & سن المبحوثين \\
\hline$* *, r \vee \leq$ & $* * \cdot, r \cdot r$ & $* *, Y Y I$ & المستوى التعليمي للمبحوثين \\
\hline$\cdot, 1 \mathrm{\mu}$ & **, r r. & $*, \Upsilon \wedge \wedge$ & المستوى التعليمي للأبناء \\
\hline$\cdot, \cdot T V$ & $* *, r$ rq & $* *, Y Y$ & عدد أفراد الأسرة" \\
\hline$* \cdot, 170$ & $* *, Y \backslash V$ & $* *, r Y V$ & الحيازة الأرضية الزراعية \\
\hline$* *, Y \uparrow$. & $* *, Y \mid r$ & ***, & عضوية المنظمات \\
\hline$* *, r, r$ & $* \cdot, 17 r$ & $* *, Y \cdot V$ & قيادة الرأي \\
\hline$* \cdot, 171$ & $*, 194$ & **, ש & الاستعداد للتغيير \\
\hline$* *, r V I$ & $\cdot, \cdot V V$ & $* *, r \cdot r$ & دافعية الإنجاز \\
\hline$* *, r \cdot V$ & $* *, r) \wedge$ & $* *, \varepsilon\} \uparrow$ & الاتجاه نحو الارشاد الزراعي \\
\hline$\cdot, 11 \leq$ & $\cdot, \cdot \leq 9$ & & الاستبصسار الوجداني \\
\hline$* *$, , $0 \leq$ & $* *,, \varepsilon \vee \leqslant$ & $* *$, or. & الميل الاستثماري " \\
\hline
\end{tabular}


المنظمــات، وقيــادة الـرأي، الاسـتعداد للتغييـر ، ودافعيــة

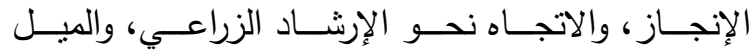
الاستثماري، تؤثر مجتمعه معنويًا في الإنفتاح الإلكتروني الإني

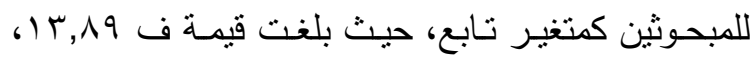

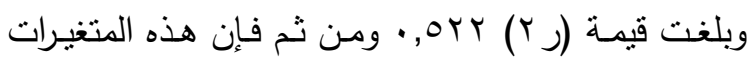

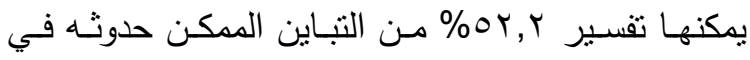
الإنفتاح الإلكتروني للمبحوثين كمتفير تابع، (جدول (1). ممـا سبق يرفض الفرض الصفري وبالتالي يمكن قبول

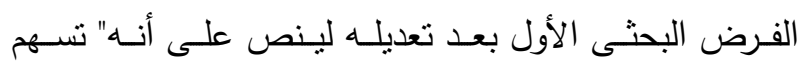

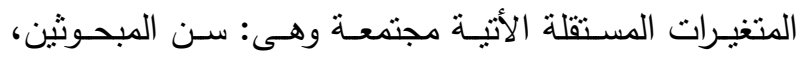
والمستوى التعليمي للمبحوثين، والمستوى التعليمي للأبناء،

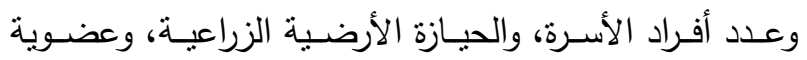

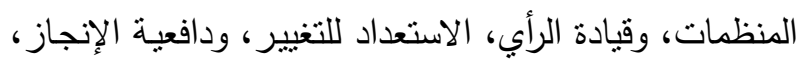
والاتجاه نحو الإرشاد الزراعي، والميل الاستثماري في تفسير التبـاين الممكن حدوثه في الإنفتاح الإلكترونسى للمبحـثين الإنين

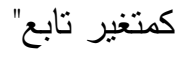

وكانت العلاقة سلبية ومعنويـة عند المستوى الاحتمـالي ا ., • مع متغير سن المبحوثين، في حين لم يتضح قيام

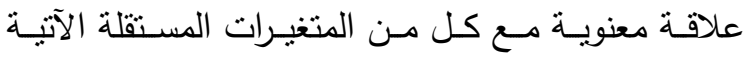

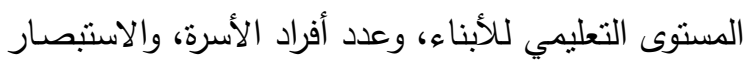

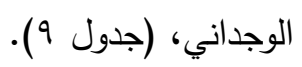

وفـي ضــوء نتـائج العلاقـات الارتباطيـة السـابقة بـين

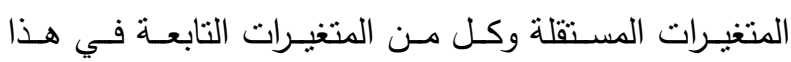
البحث، فقـد اسـتخدم اسـلوب التحليـل الانحـدارى المتعـدـ،

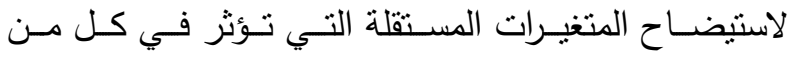

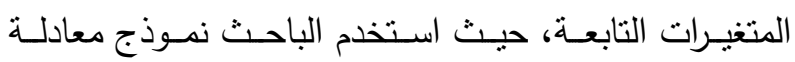
الانحدار الخطى المتعدد، وقد تبين ما يلي:

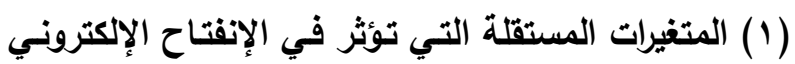

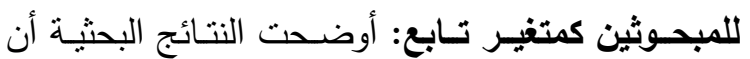

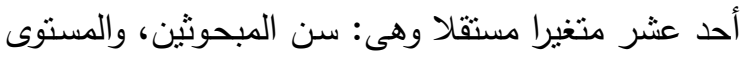

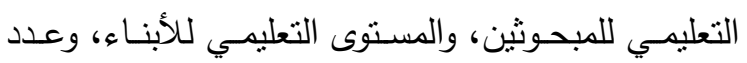

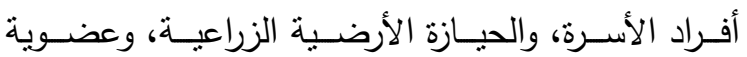

جدول • 1. التحليل الإنحارى المتعدد بين المتغيرات المستقلة والإنفتاح الإكتروني للمبحوثين كمتفير تابع

\begin{tabular}{|c|c|c|c|}
\hline 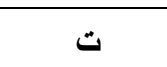 & معامل الانحدار الجزئي القياسي & معامل الانحدار الجزئي & المتغيرات المستقلة \\
\hline$* * \xi, \backslash \wedge \Gamma-$ & •,YAY- & ., Yrq- & سن المبحوثين \\
\hline .,ETr &.,$\cdot T V$ & $\cdot, 111$ & المستوى التعليمي للمبحوثين \\
\hline $1, \varepsilon \wedge$ &., 111 & . rV. & المستوى التعليمي للأبناء \\
\hline 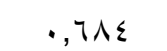 & $\cdot, \cdot \leq \varepsilon$ & r & عدد أفراد الأسرة \\
\hline - & $\cdot, \cdot \leq \leqslant-$ & $\cdot, \cdot, r-$ & الحيازة الارضبة الزراعبة \\
\hline $1, \wedge \mathrm{V}$ & 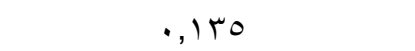 & , D & عضوية المنظمات \\
\hline$\cdot, \cdot, \varepsilon-$ & $\cdot, \ldots r-$ & $\cdot, \cdots 9-$ & قيادة الرأي \\
\hline$*$ *r, r & $\cdot, 194$ & $\cdot, r r$ & الاتجاه نحو الارشاد الزراعي \\
\hline$* * \Upsilon, q \leq$ & $\cdot, 191$ & •,Ar & الاستعداد للتغيير : \\
\hline$* * 0, \wedge 9$ & $\cdot, \varepsilon 17$ & $r, r q$ & الميل الاستثماري \\
\hline$* * \uparrow, q \vee-$ & • & ., ory- & دافعية الإنجاز \\
\hline
\end{tabular}


سن المبحوثين، والمستوى التعليمي للمبحوث، والمستوى التعليمسي للأبنـاء، وعدد أفراد الأسـرة، والحيـازة الأرضية ولية

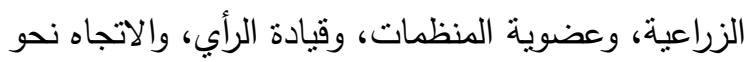

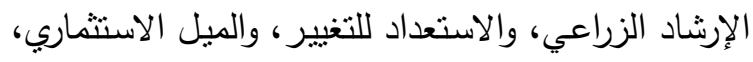
تؤئز مجتمعسه معنوَيا عند المستوى الإحتمالي ا +, , في اسـتفادة المبحـوثين مسن المواقع والتطبيقـات الالكترونيـة

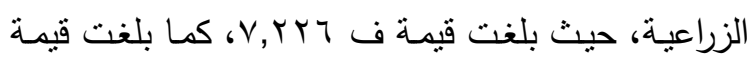

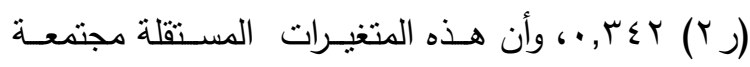

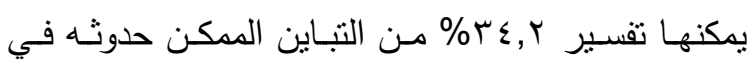

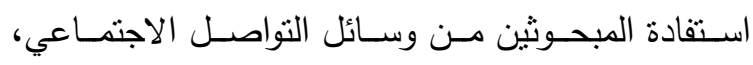

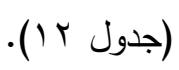

مما سبق يـرفض الفرض الصفري وبالتالي يمكن قبول

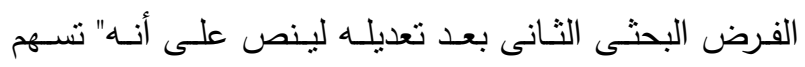

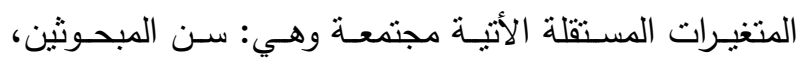
والمسـتوى التعليمسي للمبحـوث، والمسـتوى التعليهـي للأبنـاء،

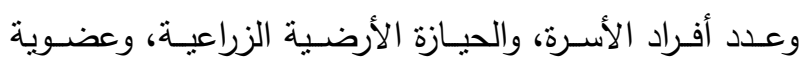

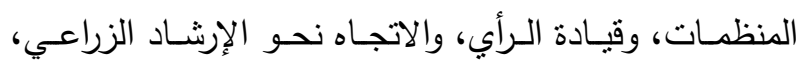
والاسـتعداد للتغييـر ، والميـل الاسـتماري في تقسـير التبـاين الممكن حدوثه في استفادة المبحوثين من المواقع والنطبيقات الالكترونية الزراعية كمتغير تابع"
ولكي يتعرف الباحث على أكثر المتغيرات المستقلة تأثيراً في الإنفتاح الإلكتروني للمبحوثين كمتغير تابع فقد استخدم أسلوب التحليل الإنحدارى المتعدد التدريجي بالإضافة خطوة الإنسئين خطوة، وقد أوضحت النتائج ما يلي: أن سبع متغيرات مستقلة فقط، وهم: الميل الاستثماري، وسـن المبحـثثين، والاسـتعداد للتغيير ، وعضـوية المنظمـات،

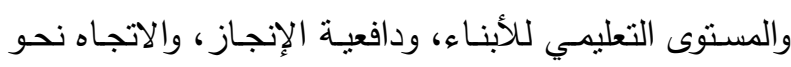
الإرشـاد الزراعي، مجتمعـة هـي الأكثر تـأثنرًا في الإنفتـاح

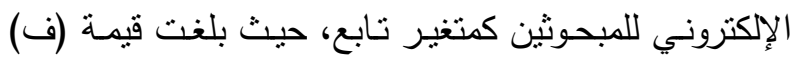
క

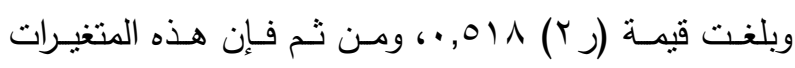

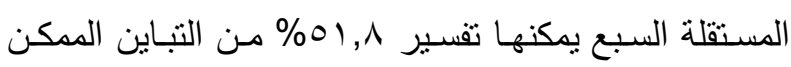

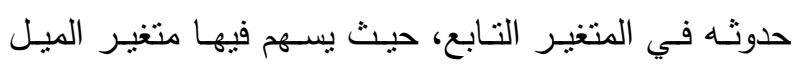

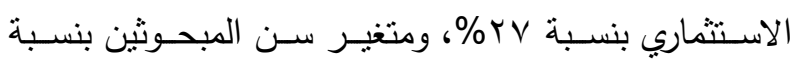

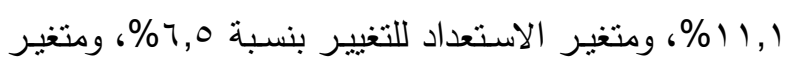
عضوية المنظمات بنسبة 9, 1\%، ومنغير المستوى التعليمي للأبناء بنسبة V, ا \%)، ودافعية الإنجاز بنسبة ^, (1، والاتجاه

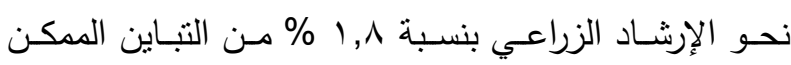
حدوثه في المتغير التابع، (جدول (1). (r) المتغيرات المستقلة المؤثرة في استفادة المبحوثين من المواقع والتطبيقات الالكترونيـة الزراعيـة كمتغير تـابع: أوضحت النتائج البحتية أن عشرة متغيرات مستقله وهى:

جدول الـ نتائج التحليل الإنحدارى المتعدد بالإضافة بين المتغيرات المستقلة والانفتاح الإكتروني للمبحوثين كمتغير تابع

\begin{tabular}{|c|c|c|c|c|}
\hline ف & \% للتباين المفسر & \% التراكمية للتباين المفسر & المتغيرات الداخلة في التحليل & الخطوة \\
\hline$* * \Delta \xi, \wedge \mathrm{V}$ & $r V, \cdot$ & $r V_{,} \cdot$ & الميل الاستثماري & 1 \\
\hline$* * \varepsilon 0, r .0$ & 11,1 & rᄉ, l & سن المبحوثين " & r \\
\hline$* * r q, r$ & 7,0 & $\varepsilon \varepsilon, 7$ & الاستعداد للتغيير & r \\
\hline **r & 1,9 & $\varepsilon\rceil, \varepsilon$ & عضوية المنظمات & $\varepsilon$ \\
\hline$* * Y \neg, \vee \backslash \neg$ & $1, \mathrm{~V}$ & $\leq \wedge, 1$ & المستوى التعليمي للأبناء & 0 \\
\hline$* * r r, \vee \backslash 1$ & 1,1 & $\leq 9,9$ & دافعية الإنجاز " & 7 \\
\hline 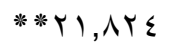 & 1,1 & 01,1 & الاتجاه نحو الإرشاد الزراعي & $\checkmark$ \\
\hline
\end{tabular}


جدول rا ا. نتائج التحليل الإنحارى بالإضافة بين المتغيرات المستقلة واستفادة المبحوثين من المواقع والتطبيقات الاكترونية

الزياعية كمتغير تابع

\begin{tabular}{|c|c|c|c|}
\hline$ت$ & معامل الانحدار الجزئي القياسي & معامل الانحدار الجزئى & المتغيرات المستقلة \\
\hline$\cdot \cdot$, Aтr- & $\cdot, \cdot 7 V-$ & $\cdot, .99-$ & سن المبحوثين \\
\hline$* r, 11 v$ & $\cdot, 101$ & $1,9 \cdot r$ & المستوى التعليمي للمبحوث \\
\hline .,0r4 & $\cdot, \cdot \leq V$ & $\cdot, 19 V$ & المستوى التعليمي للأبناء \\
\hline$* * \Upsilon, \varepsilon \vee 0$ & $\cdot, 110$ & $1, r \leq r$ & عدد أفراد الأسرة \\
\hline$\cdot, 01 \leq$ & $\cdot, \cdot \leq 1$ & $\cdot, \cdot Y_{1}$ & الحيازة الأرضية الزراعية \\
\hline$\cdot, Y \wedge \vee$ & $\cdot, \cdot r \leq$ & דו & عضوية المنظمات \\
\hline$\cdot, 17 \leq$ & $\cdot, .10$ & $\cdot, \cdot v_{0}$ & قيادة الرأي \\
\hline$\cdot, V \cdot r$ & זT •, & $\cdot, \lambda$ & الاتجاه نحو الارشاد الزراعي \\
\hline $1, \cdot \leq \wedge$ & $\cdot, \cdot \vee \vee q$ & $\cdot, 09$ & الاستعداد للتغيير الي \\
\hline$* * \varepsilon,|r|$ & • TrV & $r, I T V$ & الميل الاستثمارى \\
\hline
\end{tabular}

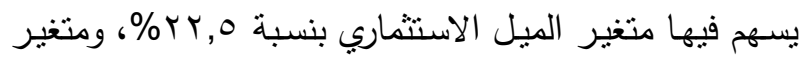

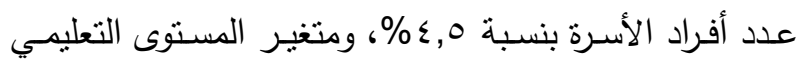

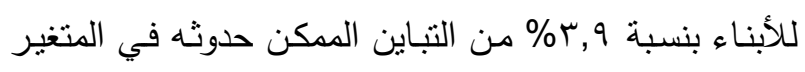

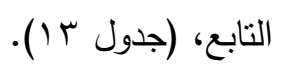

( ) المتغيرات المسـتقلة المؤيثرة في اتجاهـات المبحوثين نحو المواقع والتطبيقـات الالكترونيـة الزراعيـة كمتغير تابع: أوضحت النتائج البحثية أن تسع متغيرات مستقله وهـى: سـن المبحوثين، والمسـتوى التعليمي للمبحـوثين، والحيازة الأرضية الزراعيـة، وعضوية المنظمات، وقيادة ولئية

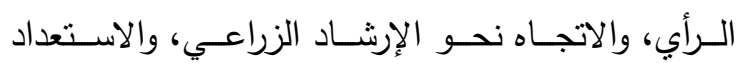
للتغيير ، والميل الاستثماري،
ولكي يتعرف الباحث على أكثر المتغيرات المستقلة تأثنراً في اسـتفادة المبحـوثين مـن المواقـع والتطبيقـات الالكترونيـة الزراعية كمتغير تابع فقد استخدم أسلوب التحليل الإنحدارى المتعـدد التـدريجي بالإضـافة خطـوة خطـوة، وقـد أوضـــت النتائج المبينة في جدول (س (I) ما يلي: أن ثناثة متغيرات مستقلة فقط، وهم: الميل الاستثماري، وعدد أفراد الأسـرة، والمستوى التعليمي للمبحوثين، مجتمعـة فئنة

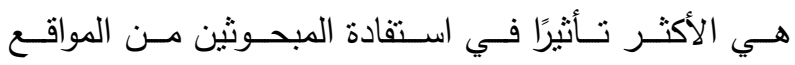

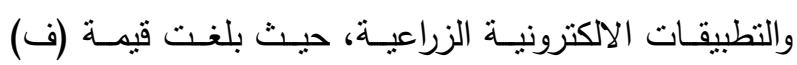
ع وأن هذه المتغيرات المستقلة الثناث مجتمعسه يمكنها تقسير 9, • ب\% من التباين الممكن حدوثه في المتغير التابع، حيث

جدول ب ا. ـ نتائج التحليل الإنحدارى المتعدد بالإضافة بين المتغيرات المستقلة واستفادة المبحوثين من المواقع والتطبيقات الاكترونية الزراعية كمتغير تابع

\begin{tabular}{|c|c|c|c|c|}
\hline ف & \% للتباين المفسر & \% التراكمية للتباين المفسر & المتغيرات الداخلة في التحليل & الخطوة \\
\hline$* * \varepsilon r, q r$ & Yr,O & Yr,O & الميل الاستثماري & 1 \\
\hline$* * Y V, I Y$ & $\varepsilon, 0$ & $r v, \cdot$ & عدد أفراد الاسرة & r \\
\hline$* * Y, T V$ & $r, q$ & $r \cdot, q$ & المستوى التعليمى للمبحوثين & r \\
\hline
\end{tabular}


ولكي يتعرف الباحث على أكثر المتغيرات المسنقلة تأثيراً في اتجاهات المبحوثين نحو المواقع والتطبيقات الالكترونيـة

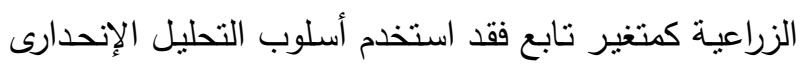

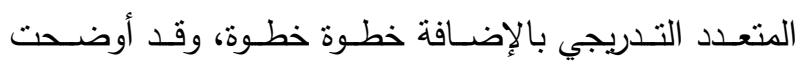
النتائج المبينة في جدول (10) ما يلي:

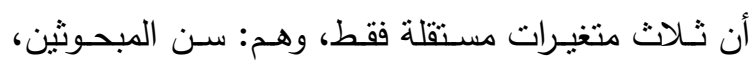

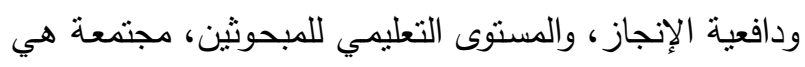

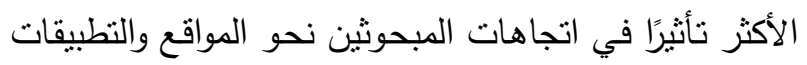

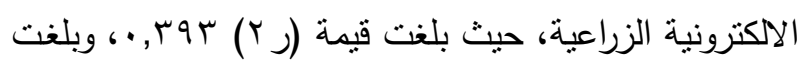

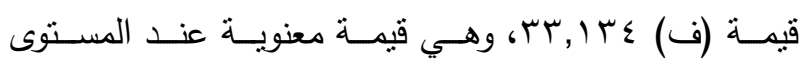

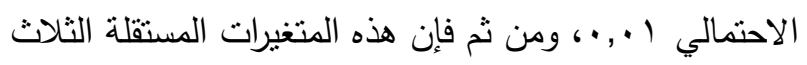

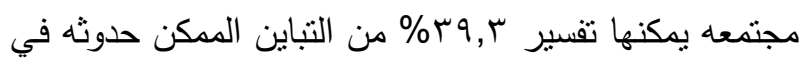

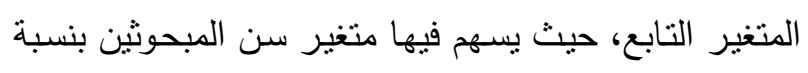

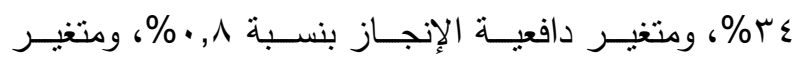

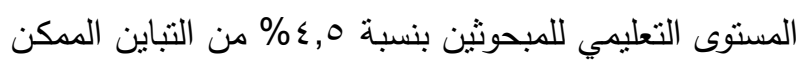

$$
\text { حدوثه في المتغير التابع، (جدول } 1 \text { (1). }
$$

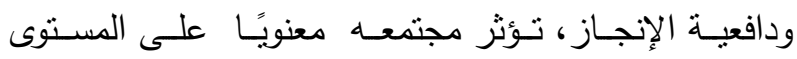

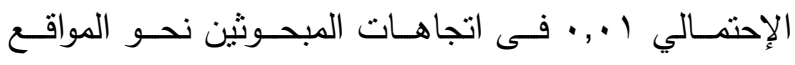

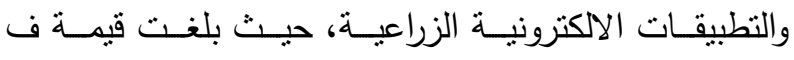

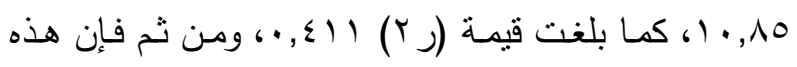

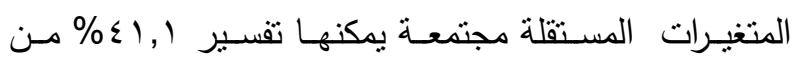

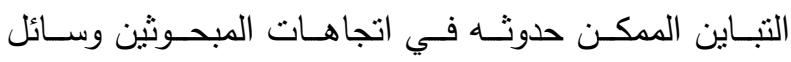

$$
\text { التواصل الاجتماعي، (جدول ؟ ( ). }
$$

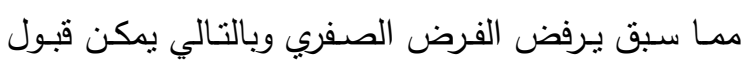
الفرض البحثى الثالث بعد تعديلـه لينص على أنـه" تسهرج

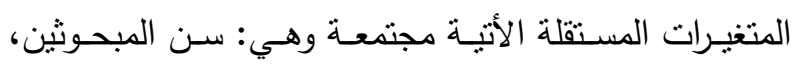

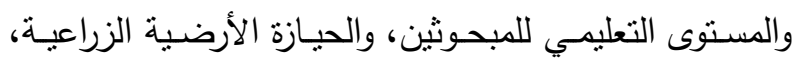

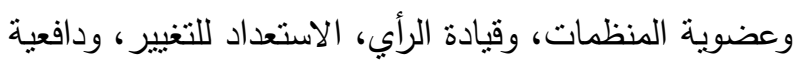

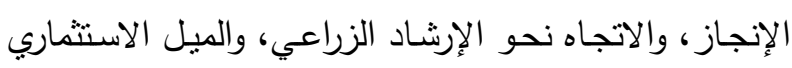

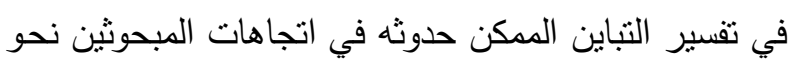

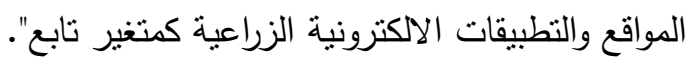
جدول ؛ ا. نتائج التحليل الإنحدارى بالإضافة بين المتغيرات المستقلة واتجاهات المبحوثين نحو المواقع والتطبيقات

\begin{tabular}{|c|c|c|c|}
\hline$ت$ & معامل الانحدار الجزئي القياسى & معامل الانحدار الجزئى & المتغيرات المستقلة \\
\hline 7,OY- & $\cdot, \varepsilon \wedge-$ & $\cdot, r \wedge \Lambda-$ & السن \\
\hline 1, vo & תז & . Y Y Y & المستوى التعليمي للمبحوث \\
\hline o & $\cdot, \cdot 1$ & $\cdot, \cdot r$ & الحبازة الأرضية الزراعية \\
\hline$\cdot, \varepsilon r v$ & $\cdot, \cdot r \varepsilon$ & $\cdot, ., \mathrm{V}$ & عضوية المنظمات \\
\hline$\cdot, \mathrm{V} T \mathrm{~V}$ & $\cdot, .70$ & $\cdot, .9$ & الاتجاه نحو الارشاد الزراعي \\
\hline$\cdot, \cdot \wedge \varepsilon$ & $\cdot, \cdots 7$ & $\cdot, \cdot r)$ & الاستعداد للتغيير \\
\hline • & $\cdot, .10$ & $\cdot, 110$ & الميل الاستثمارى \\
\hline$\cdot, r \wedge \Lambda-$ & $\cdot, \cdot r$. & $\cdot, \cdot V T_{-}$ & قيادة الرأي \\
\hline$r, 10 \xi$ & $\cdot, I V V$ & $\cdot, T V \varepsilon$ & دافعية الإنجاز \\
\hline
\end{tabular}
الالكترونية الززاعية كمتغير تابع 
جدوله ا. نتائج التحليل الانحدى المتعدد بالإضافة بين المتغيرات المستقلة واتجاهات المبحوثين نحو المواقع والتطبيقات الالكترونية الزراعية كمتغير تابع

\begin{tabular}{|c|c|c|c|c|}
\hline ف & \% للتباين المفسر & \% التراكمية للتباين المفسر & المتغيرات الداخلة في التحليل & الخطوة \\
\hline$* * \vee \neg, 1 Y$ & $\cdot, r \varepsilon$ & $\cdot, r \varepsilon$ & سن المبحوثين س & 1 \\
\hline$* * \leqslant 0, \wedge 9$ & $\cdot, \wedge$ & $r \varepsilon, \wedge$ & دافعية الإنجاز & r \\
\hline **r, & $\varepsilon, 0$ & $r q, r$ & المستوى التعليمى للمبحوثين & $r$ \\
\hline
\end{tabular}

ذللك تم رفض الفرض الصفري وقبول الفرض البحثى الرابع الذي ينص على أنسه "توجد فـروق معنويـة بـين

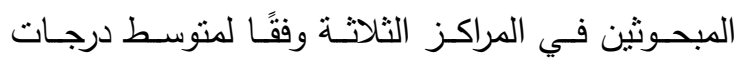

$$
\text { انفتاحهم الإكتروني، (جدول } 7 \text { (1). }
$$

ومن ناحية أخرى تبين وجود فرق معنوى بين متوسطى درجـات إنفتاح المبحوثين في مركزى دمنهور وكفر الدوار

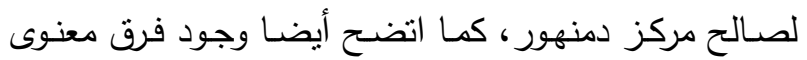
بين درجات المبحوثين في مركزى إيتاى البارود وكفر الدوار لصالح مركز إيتاى البارود، (جدول IV).
رابعًا: الفروق بين متوسطات درجات المبحوثين في مركز ايتاى البارود وكفر الدوار ودمنهور من حيث كل من الإنفتاح الالكتروني، والاستفادة من المواقع والتطبيقات الاكترونية الزراعية، واتجاهاتهم نحوها: (1) اتضح من دراسة الفروق بين متوسطات درجات الإنفتاح الإلكتروني للمبحوثين في المراكز الإداريـة الثلاثة وذلك

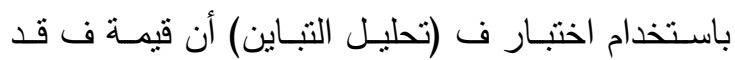
بلغت ب ؟ 7, 7 وهي قيمة معنوية عند المسنوى الاحتمالي ا •, • , ومؤدى ذلك وجود فروق معنوية بين متوسطات الإنفتاح الإكتروني للمبحوثين في المراكز الثناثة وعلى

جدول 1 ـ متوسطات درجات الإنفتاح الإكتروني للمبحوثين في المراكز الإدارية الثلاثة المدروسة

\begin{tabular}{cccc}
\hline F & المتغير & \\
\hline & الانفتاح الإكتروني & \\
\hline
\end{tabular}

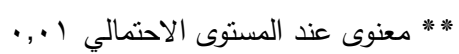

جدول V ا. اختبار اقل فرق معنوي LSD بين متوسطات درجات الإنفتاح الإكترونـي للمبحوثين في المراكز الإداريـة الثلاثة المدروسةة

\begin{tabular}{|c|c|c|c|c|}
\hline دمنهور & كفر الدوار & ايتاى البارود & المراكز & المتغيرات \\
\hline $1,7 \varepsilon$ & $* \varepsilon, Y\urcorner$ & ---- & ايتاى البارود & \\
\hline$* 0,9$. & ------- & $* \varepsilon, Y \uparrow$ & كفر الدوار & الانفتاح الإلكتروني \\
\hline ------ & $* 09$. & $1,7 \varepsilon$ & دمنهور & \\
\hline
\end{tabular}


اتضــح مـن دراســة الفـروق بـين متوسـطات درجـات اتجاهـات المبحوثين نحو المواقـع والتطبيقـات الالكترونيـة الزراعية في المراكز الإدارية الثناثة المدروسة في المراكز

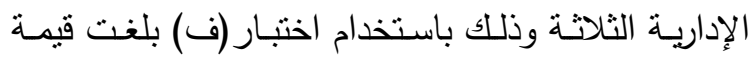

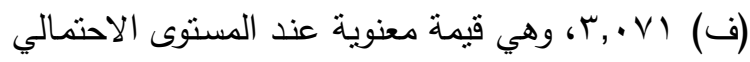
ه . • • ومؤدى ذلك وجود فروق معنوبـة بين متوسطات اتجاهـات المبحـوثين في المراكز الثلاتثة وعلى ذلك تم رفض الفـرض الصـفري وقبـول الفرض البحثى السـادس أنس الذى ينص على انه توجد فروق معنويـة بين المبحوثين

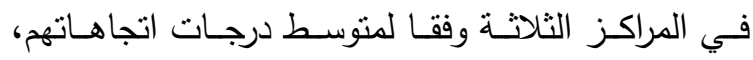

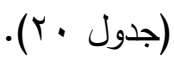

ومـن ناحيـة أخرى تبين وجـود فرق معنوى بين متوسط درجات اتجاهات المبحوثين في مركزى دمنهور وايناى البارود لصالح مركز دمنهور ، (جدول (Y).

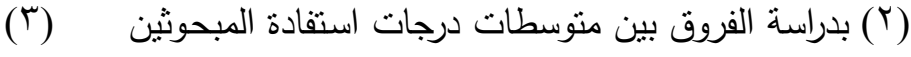
من المواقع والنطبيقات الالكترونية الزراعية في المراكز

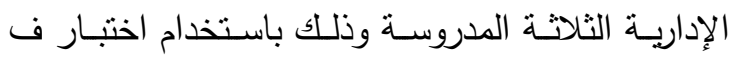
بلغت قيمـة (ف) r, r وهى قيمـة معنويـة عند المسنتوى الاحتمـالي 0 . , • ومؤدى ذلك وجود فروق معنويـة بين

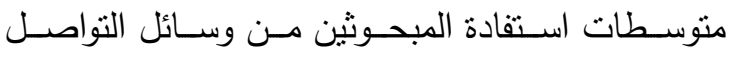
الإجتماعى في المراكز الإدارية الثلاثة المدروسـة وعلى ذلك تم رفض الفرض الصفري وقبول الفرض البحنى الخامس الذى ينص على انها نوجد فروق معنويـة بين

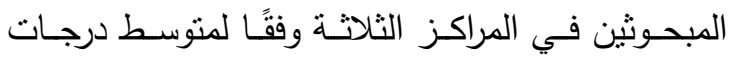
استفادتها من وسائل التواصل الاجتماعي، (جدول ^1 ). ومن ناحية أخرى تبين وجود فرق معنوى بين متوسطى درجات استفادة المبحوثين في مركزى دمنهور وايتاى البارود من ناحيبة والمتوسط المناظر فى مركز كفر الدوار لصـالح مركزى ايتاى البارود ودمنهور ، (جدول 9 (1).

جدول ^ا. متوسطات درجات استفادة المبحوثين من المواقع والتطبيقات الاكترونية الزراعية في المراكز الإدارية الثلاثة المدروسةة

\begin{tabular}{|c|c|c|c|}
\hline $\mathbf{F}$ & المتوسطات & المراكز & 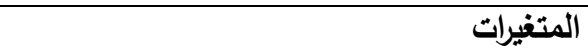 \\
\hline & $r Y, \Sigma \wedge$ & ايتاى البارود & \\
\hline \multirow[t]{2}{*}{$* r, r$} & $10, \mathrm{r} \Lambda$ & كفر الدوار & الاستفادة المواقع والتطبيقات الاككترونية الزراعية \\
\hline & $r \cdot, 9 \varepsilon$ & دمنهور & \\
\hline
\end{tabular}
* معنوى عند المستوى الاحتمالي . .,

جدول 9 ـ. اختبار اقل فرق معنوي LSD بين متوسطات درجات استفادة المبحوثين من المواقع والتطبيقات الاككترونية الزراعية في المراكز الإدارية الثلاثة المدروسة

\begin{tabular}{|c|c|c|c|c|}
\hline دمنهور & كفر الدوار & ايتاى البارود & المراكز & 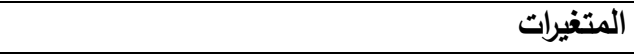 \\
\hline $1,0 \leqslant$ & $* \vee, 1$ & ---- & ايتاى البارود & \\
\hline$* 0,07$ & ------- & $* \vee, 1$ & كفر الدوار & الاستفادة من المواقع والتطبيقات الاككترونية الزراعية \\
\hline---- & $* 0,07$ & $1,0 \leqslant$ & دمنهور & \\
\hline
\end{tabular}


جدول · r. متوسطات درجات اتجاهات المبحوثين نحو المواقع والتطبيقات الاككترونية الزراعية في المراكز الإدارية الثلاثة

المدروسة

\begin{tabular}{|c|c|c|c|}
\hline $\mathbf{F}$ & 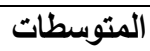 & المراكز & 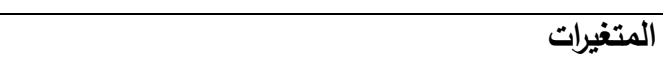 \\
\hline \multirow{3}{*}{$* r, \cdot v 1$} & $r q, r ч$ & ايتاى البارود & الاتجاهات نحو المواقع والتطبيقات الآكترونية الزراعية \\
\hline & ri,r & كفر الدوار & \\
\hline & 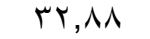 & دمنهور & \\
\hline
\end{tabular}

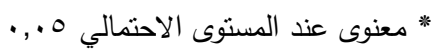

جدول اب. اختبار اقل فرق معنوي LSD بين متوسطات درجات اتجاهات المبحوثين نحو المواقع والتطبيقات الاكترونية

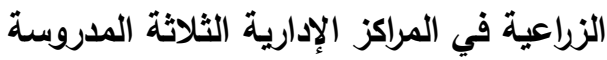

\begin{tabular}{|c|c|c|c|c|}
\hline دمنهور & كفر الدوار & ايتاى البارود & المراكز & المتغيرات \\
\hline$* * r, O Y$ & $1,9 \leq$ & --- & ايتاى البارود & الاتجاهات نحو المواقع والتطبيقات الالكترونية الزراعية \\
\hline 1,01 & ------- & $1,9 \varepsilon$ & كفر الدوار & \\
\hline ---- & 1,01 & $* * Y, O Y$ & دمنهور & \\
\hline
\end{tabular}

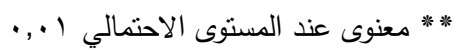

ويلاحظ من النتائج السابقة الخاصة بالفروق بين الدوار إلى قرب مسافة إيناى البارود من مدينة دمنهور

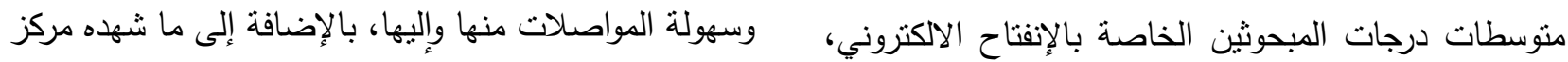

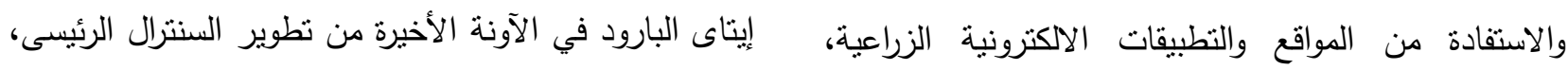

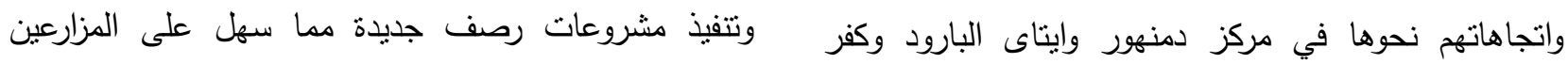

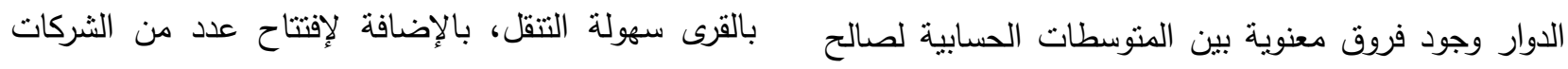

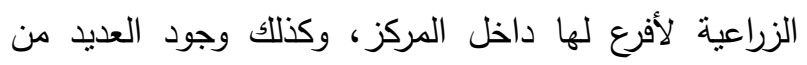

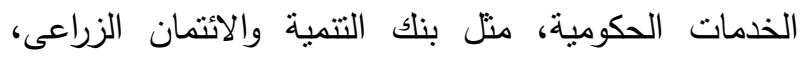
ومحطة البحوث الزراعية بأقسامها المختلفة.

\section{المراجع}

أثنرتون، بولين، 1997، مراكز المعلومات وتنظيمها وادارتها وخدماتها، ترجمة حشمت قاسم، دار غريب للطباعة والنشر والتززيع.

الجويلى، سمير إبراهيم حسين، 1...r، استفادة المرشدين الزراعيين والزراع من شبكة اتصال البحوث بالإرشاد الزراعي الئي (فيركون) بمحافظتي كفر الثيخ والبحيرة، رسالة ماجستير ، كلية الزراعة، جامعة الإسكندرية - فرع دمنهور . المبحوثين في مركز دمنهور يليه المنوسطات الحسابية للمبحوثين في مركز إيتاى البارود، وقد يرجع هذا الفرق إلى ما يتمتع به مركز دمنهور من بنية تحتية تمكن من إستخدام

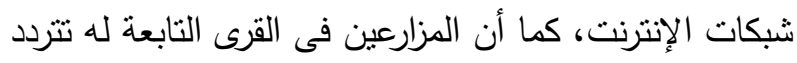
بشكل دورى على مدينة دمنهور وهى عاصمة محافظة البحيرة، وذللك للحصول على كثير من الخدمات ومستلزمات

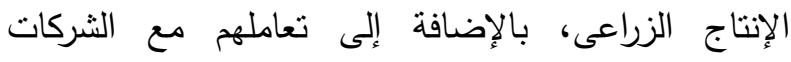
والوكالات التجارية الزراعية العديدة المتواجدة بمدينة دمنهور

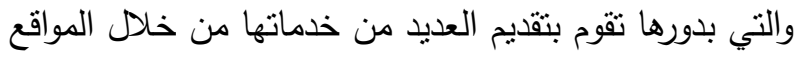
والتطبيقات الإلكترونية، كل ذلك من شأنه أن يعظم من درجة

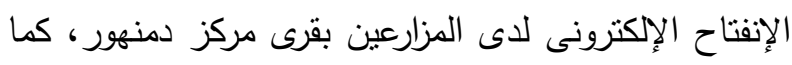
يرجع تفوق متوسطات درجات المبحوثين في مركز إيتاى لإن البارود على منوسطات درجات الدبحوثين في مركز كفر 


$$
\begin{aligned}
& 2209 \\
& \text { الإرشادي، المجلة الأردنية المجلد ال، العدد Y، ص ص: } \\
& .00 .049 \\
& \text { قاسم، حازم صلاح منصور ، } 10 \text { • ب، سلوك الزراع في البحث عن } \\
& \text { المعلومات ببعض مراكز محافظتي كفر الثيخ والبحيرة، مجلة } \\
& \text { جامعة المنصورة للعلوم الزراعية الاقتصادية والإجتماعية، مجلد }
\end{aligned}
$$

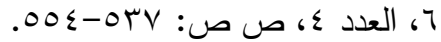

$$
\begin{aligned}
& \text { قاسم، محمد حسن، ب . . ץ، المستقيدون من شبكة اتصال البحوث }
\end{aligned}
$$

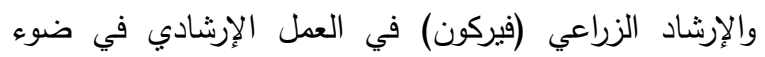

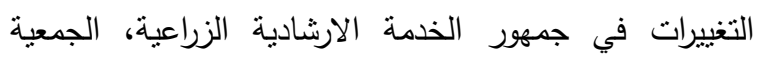

$$
\begin{aligned}
& \text { العلمية للإرشاد الزراعي، المؤتمر السابع. }
\end{aligned}
$$

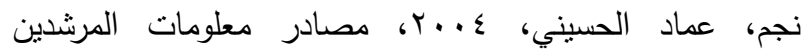

$$
\begin{aligned}
& \text { الزراعيين في مصر، رسالة دكتوراه في العلوم الزراعية، كلية }
\end{aligned}
$$

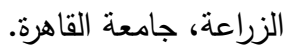$$
\text { مصطفي صبري مصطفى صالح وأخرون.،: الإنفتاح الإلكتروني لأعضاء مجالس إدارات الجمعيات التعاونية الزراعية ... }
$$

Hill,M. 2012.Using Farmer's Information Seeking Behavior to Inform the Design of Extension. Extension Farming Systems Journal. 5(2), pp.121-126.

Renwick, S. 2009. Potential for Use of Information and Communication Technologies (ICTs) in Agricultural Extension, Paper submitted for AGEX 6003 - Trends and Emerging Issues in Extension, April 21, 2009

Online available at: http://www.uwispace.sta.uwi.edu

$$
\begin{aligned}
& \text { العبد، عمر، ه . . ب، الزراعة والمجتمع والمعلومات، تعلم الانترنت } \\
& \text { من اهم المواقع الزراعية، دار الكتب العلمية للنشر والتوزيع، }
\end{aligned}
$$

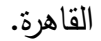

$$
\begin{aligned}
& \text { العلمى، حسين، با.بr، دور الاستثمار فى تكنولوجيا المعلومات } \\
& \text { والاتصالات في تحقيق التتمية المستدامة (دراسة مقارنة بين } \\
& \text { ماليزيا، وتونس، والجزائر)، رسالة ماجستير، كلية العلوم } \\
& \text { الاقتصادية والعلوم التجارية وعلوم التفسير، جامعة سطيف، }
\end{aligned}
$$

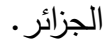

$$
\begin{aligned}
& \text { تربان، ماجد سالم، ^ . . ץ، الإنترنت والصحافة الإلكترونية رؤية } \\
& \text { مسنقبلية، الدار المصرية اللبنانية للنشر ، القاهرة. } \\
& \text { عبد الغنى، محمد محمد، } 9 \text { ـ ب، دراسة لجاهزية استخدام وسائل } \\
& \text { النواصل الاجتماعى فى الإرشاد الزراعى بمحافظة اسبوط، }
\end{aligned}
$$

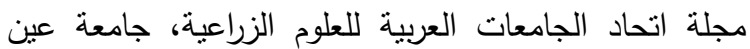

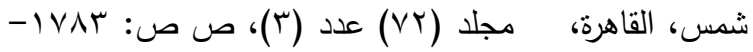

$$
\begin{aligned}
& .11 .1
\end{aligned}
$$

عبد الواحد، منصور أحمد محمد حفنى، 10 • r، استخدام العاملين بالإرشاد الزراعي لتكنولوجيا المعلومات والاتصالات في العمل

\title{
ABSTRACT \\ Board Members of Agricultural Cooperative Societies' Electronic Openness, their Benefit from Agricultural Websites and Application, and their Attitudes Toward It, in Some Districts in El-Behaira Governorate
}

\author{
Moustafa Sabry Moustafa Saleh, Mai Ahmed Rafaat El-Tatawy and Mohamed Sabry Moustafa \\ Saleh
}

The current research is mainly aiming to study Board members of Agricultural Cooperative Societies' Electronic Openness, And their Benefits from agricultural websites and application, and their attitudes toward it, in some districts in El-Behaira Governorate. Data was collected by a questionnaire through personal interview for a random sample of 150 subjects from 3 districts, Researcher used several statistical methods including percentages, means, frequencies, (f) test, standard deviation, simple correlation, and multiple regression analysis.

The most important results are summarized as follows:
1. The results showed that $(86.85 \%)$ of the researched farmers have medium and low electronic openness.

2. The results showed that $(72.6 \%)$ of the researched farmers have medium and low social media benefits from agricultural websites and application.

3. The results showed that $(66.7 \%)$ of the researched farmers have negative and neutral attitude toward agricultural websites and application.

Key words: Electronic Openness- Agricultural Cooperative Societies'- agricultural websites and application - attitudes toward agricultural websites and application - agricultural websites and application benefits. 